\title{
CAMA
}

Centre for Applied Macroeconomic Analysis

\section{Do central banks respond timely to developments in the global economy?}

\section{CAMA Working Paper 20/2017 March 2017}

Hilde C. Bjørnland

BI Norwegian Business School

Norges Bank and

Centre for Applied Macroeconomic Analysis, ANU

Leif Anders Thorsrud

BI Norwegian Business School

Norges Bank

\section{Sepideh Khayati Zahiri}

BI Norwegian Business School

\section{Abstract}

Our analysis suggests; they do not! To arrive at this conclusion we construct a real-time data set of interest rate projections from central banks in three small open economies; New Zealand, Norway, and Sweden, and analyze if revisions to these projections (i.e., forward guidance) can be predicted by timely information. Doing so, we find a systematic role for forward looking international indicators in predicting the revisions to the interest rate projections in all countries. In contrast, using similar indexes for the domestic economy yields largely insignificant results. Furthermore, we find that revisions to forward guidance matter. Using a VAR identified with external instruments based on forecast errors from the predictive regressions, we show that the responses to output, inflation, the exchange rate and asset returns resemble those one typically associates with a conventional monetary policy shock. 


\title{
Keywords
}

Monetary policy, interest rate path, forecast revisions and global indicators

\author{
JEL Classification
}

C11, C53, C55, E58, F17

\section{Address for correspondence:}

(E) cama.admin@anu.edu.au

\section{ISSN 2206-0332}

The Centre for Applied Macroeconomic Analysis in the Crawford School of Public Policy has been established to build strong links between professional macroeconomists. It provides a forum for quality macroeconomic research and discussion of policy issues between academia, government and the private sector.

The Crawford School of Public Policy is the Australian National University's public policy school, serving and influencing Australia, Asia and the Pacific through advanced policy research, graduate and executive education, and policy impact. 


\title{
Do central banks respond timely to developments in
}

\author{
the global economy?*
}

\author{
Hilde C. Bjørnland ${ }^{\dagger} \quad$ Leif Anders Thorsrud ${ }^{\ddagger}$ \\ Sepideh Khayati Zahiri ${ }^{\S}$
}

March 3, 2017

\begin{abstract}
Our analysis suggests; they do not! To arrive at this conclusion we construct a real-time data set of interest rate projections from central banks in three small open economies; New Zealand, Norway, and Sweden, and analyze if revisions to these projections (i.e., forward guidance) can be predicted by timely information. Doing so, we find a systematic role for forward looking international indicators in predicting the revisions to the interest rate projections in all countries. In contrast, using similar indexes for the domestic economy yields largely insignificant results. Furthermore, we find that revisions to forward guidance matter. Using a VAR identified with external instruments based on forecast errors from the predictive regressions, we show that the responses to output, inflation, the exchange rate and asset returns resemble those one typically associates with a conventional monetary policy shock.
\end{abstract}

JEL-codes: C11, C53, C55, E58, F17

Keywords: Monetary policy, interest rate path, forecast revisions and global indicators

*We thank Efrem Castelnuevo, Renee Fry-McKibbin, James Morley, Adrian Pagan, Francesco Ravazzolo, and seminar and conference participants at Norges Bank, the Federal Reserve Bank of St. Louis, University of Melbourne, the Central Bank Macro Modelling Workshop at the Reserve Bank of New Zealand, the SNDE 2016 Annual Symposium in Tuscaloosa and the CEF 2016 Annual Meeting in Bordeaux for constructive comments and fruitful discussions. This paper is part of the research activities at the Centre for Applied Macro and Petroleum economics (CAMP) at the BI Norwegian Business School. This Working Paper should not be reported as representing the views of Norges Bank. The views expressed are those of the authors and do not necessarily reflect those of Norges Bank.

${ }^{\dagger}$ BI Norwegian Business School, Centre for Applied Macroeconomic Analysis (CAMA, ANU) and Norges Bank. Email: hilde.c.bjornland@bi.no

${ }^{\ddagger}$ Norges Bank and BI Norwegian Business School. Email: leif.a.thorsrud@bi.no

$\S$ Corresponding author: BI Norwegian Business School. Email: sepideh.k.zahiri@bi.no 


\section{Introduction}

Much applied research has shown that global developments play a large role in explaining business cycles and inflation in small and open economies, see, e.g., Kose et al. (2003), Ciccarelli and Mojon (2010), and Mumtaz et al. (2011). At the same time, the structural, small open-economy models used by many central banks to analyze and predict macroeconomic outcomes cannot account for the substantial influence of foreign-sourced disturbances identified in the numerous reduced-form studies. ${ }^{1}$ Accordingly, model-implied cross-correlation functions between the small open economies and global economies are small, while data suggest that they are positive and large.

In this paper we hypothesize that this discrepancy matters for how monetary policy is conducted, and ultimately for how central banks make revisions to their predicted interest rate paths, i.e., their announced policy intentions. Furthermore, if policymakers make revisions to the interest rate path based on their forecast failures, it will also matter for how monetary policy will affect the economy. After all, central banks announce their intentions to influence (i.e., give forward guidance to) the market. If monetary policy surprises include delayed responses to international developments, these responses may also have a marked effect on the economy.

To examine these issues, we first construct a real-time data set of interest rate projections from the central banks in New Zealand (Reserve Bank of New Zealand), Norway (Norges Bank), and Sweden (Sveriges Riksbank). We focus on these three countries as they are small and open, and because they were the first three countries adopting the practice of communicating their policy intentions explicitly by publishing their forecasts of future interest rates. ${ }^{2}$ We then examine two questions in particular: (i) whether international versus domestic indicators can predict the forecast revisions in the central bank's policy rate?, and (ii) whether fundamental variables versus forward looking variables matter? To avoid look-ahead-biases when running the predictive regressions we take care to use information that was actually available to the policy makers at the time of making

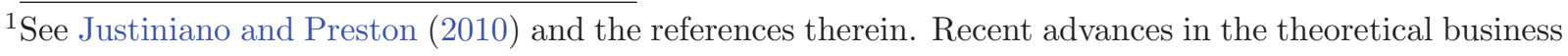
cycle literature have tried to bridge this gap between the empirical findings and theory, with Bergholt and Sveen (2013) being one example among others.

${ }^{2}$ The Reserve Bank of New Zealand was the first central bank to publish own forecast of the interest rates in 1997, followed by Norges Bank in 2005, and Sveriges Riksbank in 2007. Since then, several other central banks have followed, including the Central Bank of Iceland in 2007, the Czech National Bank in 2008 and most recently, the Federal Reserve in 2012. Accordingly, the results in this paper should be of relevance for an increasing number of central banks.
} 
their initial interest rate projections. That is, we use real-time data, that is data that are not revised, and data that were published prior to the publication of the initial interest rate path, and refer to them in short as timely data.

And indeed, running a battery of predictive regressions with domestic and foreign indicators we find that there is a systematic role for international indicators in predicting the revisions to the policy rate. Most notably is the role of forward looking foreign indicators. In contrast, using related indexes for the domestic economy yields more or less insignificant results. In addition, at least for New Zealand and Sweden, there is a close correspondence between the information sets explaining inflation and output forecast revisions and those that explain the interest rate forecast revisions.

The interest rate path published by the central bank is a forecast and not a promise. It is, presumably, the best assessment the central bank can make at a given point in time, but the path might be revised if new information arrives after the initial publication. However, if revisions to the interest rate path are predictable using timely information, as our results indicate, it means that the central bank values this information when making it's interest rate decisions, but does not incorporate it efficiently. This might have important implications. After all, one of the main motivations for central banks to publish their interest rate projections is to help shape financial market expectations and improve macroeconomic performance, c.f. Woodford (2005) and Rudebusch and Williams (2008). If the interest rate projections do not effectively incorporate the influence of international economic developments on the domestic economy, then rather than effectively shaping expectations, the forward guidance could potentially be an important source of monetary policy errors.

To examine the implications of policy makers acting on their apparent mistakes (their forecast errors), we analyze the joint response of key economic and financial variables, including market interest rates, to the implied shocks to the policy rate using a structural vector autoregressive (SVAR) model. However, rather than relying on the standard timing restrictions that is commonly done in structural VARs to identify monetary policy shocks, we use an external instrument variable (IV) approach (Stock (2008)). To answer the question of interest, the instruments are constructed from forecast errors based on the revisions to the published interest rate path. The total forecast error includes revisions to forward guidance due to both new information arriving during the forecast horizon, potentially correlated with the other shocks in the SVAR, and "old" information that could be used to predict the error. Therefore, to make sure that the identified IV shocks are orthogonal to within period movements in the other variables, we use only the part 
of the forecast error that is explained (predicted) by timely foreign variables. In so doing we focus on the forecast errors that could in principle have been avoided, had the policy makers responded more timely in the past to the informational content in international variables.

And yes, we do find that interest rate revisions matter. In particular, our structural analysis suggests that the responses in output, inflation and the exchange rate to the implied forecast errors resemble those one typically finds following a monetary policy shock. Both GDP and inflation fall sharply, while the exchange rate appreciates on impact, before depreciating back to equilibrium. The stock price also falls temporarily, but the decline is modest, suggesting asset prices to a larger extent may have anticipated these revisions.

Our study contributes to three different strands of the literature. First, as alluded to above, our analysis contributes to the large empirical literature documenting how economic fluctuations are closely connected across borders. ${ }^{3}$ While the large bulk of this literature has focused on (reduced form) cross-border synchronization of real and nominal variables, we show that the synchronization patterns potentially also matter for the conduct of monetary policy and forward guidance.

Second, our analysis relates to the growing literature that more directly identifies monetary policy shocks using unconventional measures such as forward guidance, i.e., the practice of communicating the future path of the interest rates, see e.g., Kuttner (2001), Romer and Romer (2004), Gürkaynak et al. (2005) and Gertler and Karadi (2015), among others. In particular, while Romer and Romer (2004) examined narrative records to infer the Federal Reserve's intentions for the federal funds rate around FOMC meetings, Kuttner (2001), Gürkaynak et al. (2005) and Gertler and Karadi (2015) used high-frequency (financial) data to construct anticipated and unanticipated components of monetary policy. In contrast to some of these studies, however, we do not have to go via the narrative records of the future market to construct the central banks intentions (and the corresponding forecast errors), since we have access to the actual projected interest rate paths. Moreover, we focus on shocks to forward guidance that could in principle have been avoided, had the policy makers responded more timely in the past to the informational

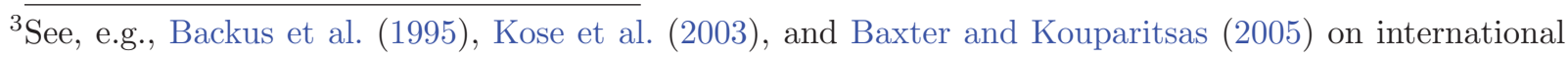
business cycle synchronization, Mumtaz and Surico (2008), Monacelli and Sala (2009) and Ciccarelli and Mojon (2010) on the co-movement of inflation rates, and Canova and Marrinan (1998), Stock and Watson (2005), Eickmeier (2007), Moneta and Rüffer (2009), Mumtaz et al. (2011), Thorsrud (2013), Bjørnland et al. (2015) and Aastveit et al. (2016) on regional and international transmissions of shocks. 
content in international variables.

Finally, our paper relates to the literature that analyzes the efficacy of forward guidance. Key to the analysis is the argument that while communicating policy intentions may give forward guidance to economic agents, (i.e., Woodford (2005)), and thereby also improve private sector's interest rate forecasts, (i.e., Swanson (2006)), past announcements might also constrain future policy decisions, as policy makers may want to stick to their plan. Consistent with this, Mirkov and Natvik (2016) show that the Reserve Bank of New Zealand and Norges Bank, the two central banks with the longest history of publishing interest rate forecasts, might have placed some weight on their latest published interest rate projections when setting the current interest rate level. Such adherence might prevent policymakers from responding timely and efficiently to unexpected shocks. Eventually, though, policy makers will have to revise their forecast. We show that when they do, some of that revision can be explained by past developments in international indicators.

The remainder of the paper is structured as follows. Section 2 describes the real time dataset of interest rate projections and the revisions to these, while Section 3 describes the predictive experiment, the data used, and result obtained. Section 4 discusses how we relate the central bank forecast revisions to potential monetary policy shocks in a SVAR using IV identification, and reports the associated impulse responses. Section 5 concludes.

\section{Interest rate projections and forecast revisions}

In the following we describe the data and explain how we construct the time series of interest rate projections and forecast revisions in the three countries. In the end we summarize the revisions series used in our analysis through a series of descriptive statistics.

\section{$2.1 \quad$ Interest rate projections}

The interest rate projections are collected from the Reserve Bank of New Zealand (RBNZ), Norges Bank (NB) and Sveriges Riksbank (SR) historical publication records. ${ }^{4}$ A detailed description of how the dataset is constructed is provided in Table 6 in Appendix A, while Figure 1 illustrates how the interest rate predictions have evolved across time in RBNZ, NB and SR, respectively. For each forecast vintage we plot the whole predicted policy

${ }^{4}$ The interest rate projections published by the RBNZ, NB and SR are the 90-bank bill rate, the key policy rate (foliorenten), and the repo rate, respectively. The sample varies, depending on when a central bank started to publish interest rate projections; 1999Q1-2015Q4 (RBNZ), 2005Q4-2015Q4 (NB) and 2007Q2-2015Q4 (SR). 
Reserve Bank of New Zealand policy rate

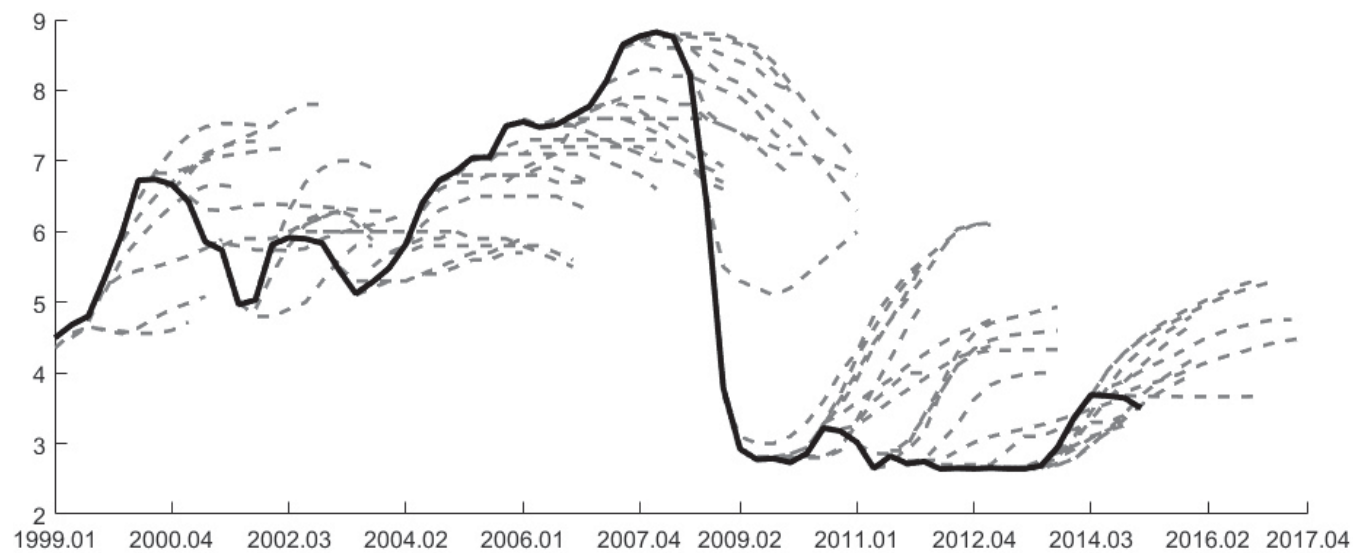

Norges Bank policy rate

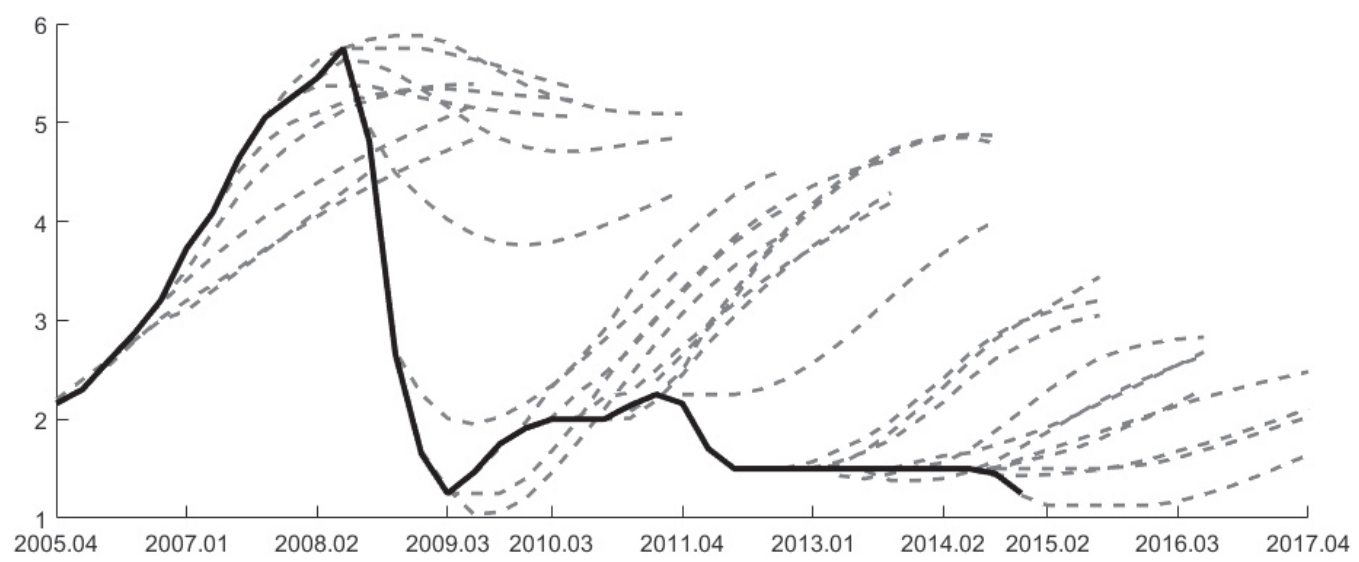

Sveriges Riksbank policy rate

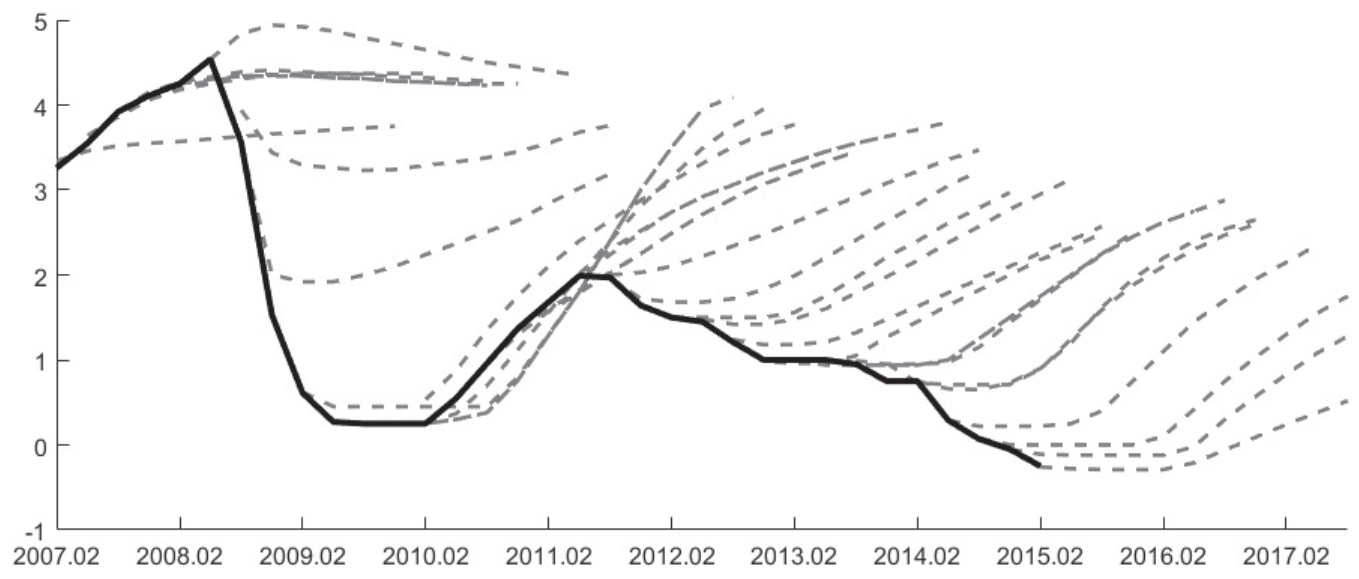

Figure 1. Central bank interest rate predictions (dotted lines) and actual outcomes (solid line).

rate path. We also report the actual outcomes. As can be clearly seen from the figures, there have at times been large revisions to the interest rate projections from one vintage to the next. We also observe that the projections are often very far off compared with the actual outcomes in all countries. The latter is maybe not that surprising given the large macroeconomic shocks that have occurred during this sample. 
An important issue when using these projections to construct forecast revisions and when investigating whether or not the revisions are predictable is timing, both (i) with regard to the information set available to the policy makers when making the (initial and updated) forecasts in each country, and (ii) with respect to the timing of forecasts across countries.

For the first issue, we record not only the actual interest rate paths, but also the exact release day of the predictions. Subsequently, when we investigate if forecast revisions are predictable, we ensure that we do not use information that was not available to the central banks at the time they made their initial forecast.

For the second issue, we observe that for many periods, both RBNZ and NB publish their forecasts late in each quarter (March, June, September and December). Hence the timing is roughly consistent across these two countries. However, in the period prior to 2012, except 2008, NB publishes only three forecasts a year (March, June and October). To obtain comparable time series for this period and country, with four quarterly observations for each year, we construct from the October report two series of forecasts: a series of forecasts for Q4 and onwards, but stored as if it was constructed in Q3, and another set of forecast for Q1 and onwards, stored as constructed in Q4. For Sweden which publishes up to six reports within a year, we pick the reports that are published as close as possible in time to the publication cycle of the two other countries. More details on the monetary policy reports and the constructed time series are provided in Table 6 in Appendix A.

\subsection{Forecast revisions}

We focus our study on forecast revisions, as opposed to forecast errors, which have been studied more extensively in related literature, see e.g. Mirkov and Natvik (2016). By looking solely at forecast errors, it would have been harder to disentangle how central banks value incremental pieces of new information. In contrast, if forecast revisions are predictable using timely information it means that the central bank values this information when making it's interest rate decisions, but does not incorporate it efficiently. Still, as we show below, there is a close correspondence between the revisions and the actual forecast errors.

To construct a time series for the revisions of the projected interest rate paths (referred

to in short as forecast revisions) we do the following: First, let $f_{2, t+1 \mid I_{t-1}}$ be the two-step ahead forecast of the policy rate given information at time $t-1$, and let $f_{1 t+1 \mid I_{t}}$ be the one-step ahead (counterpart) forecast made one quarter later and given information up 
to time $t$, i.e., the most recent forecast of the policy rate at quarter $t+1 .^{5}$ The forecast revisions between these two series (the one-step ahead and the two-step ahead forecast series) can then be found as: $r_{12, t+1} \equiv f_{1, t+1 \mid I_{t}}-f_{2, t+1 \mid I_{t-1}}$. Similarly, revisions between the two-step ahead and the three-step ahead counterpart forecast series, conditioning on time $t-1$ and $t-2$ respectively, can be found as $r_{23, t+1} \equiv f_{2, t+1 \mid I_{t-1}}-f_{3, t+1 \mid I_{t-2}}$ or more generally:

$$
r_{i j, t+1} \equiv f_{i, t+1 \mid I_{t+1-i}}-f_{j, t+1 \mid I_{t+1-j}} \text { where } i=j-1
$$

With the forecast revision definition in (1), the link between forecast revisions and actual forecast errors is simply the sum of the revisions up to the given forecast horizon $h$ :

$$
e_{h, t+1}=\sum_{j=1}^{h} r_{i j, t+1} \text { for } h>1 \text { and where } i=j-1
$$

Naturally, the forecast error at $h=1$ is identical to the revision between the one-step ahead forecast and the outcome $\left(i_{t}\right) ; e_{1, t+1}=f_{0, t+1 \mid I_{t+1}}-f_{1, t+1 \mid I_{t}}=i_{t}-f_{1, t+1 \mid I_{t}}$. However, in the analysis below we will not focus on these very short run revisions and errors. As reported in Mirkov and Natvik (2016), central banks in general seldom depart from their one-step ahead predictions, and the resulting revisions series will therefore feature very little variation. ${ }^{6}$ Likewise, we restrict ourselves to evaluating only forecasts made up to four quarters ahead, i.e., $h=4$, or $r_{34, t+1}$.

Table 1 summarizes the revisions series used in our analysis. From Panel A we observe that the mean revision increases with the horizon for all three countries, and that it varies between -10 and -20 basis points. The negative signs indicate that over the sample considered here there has been a tendency towards downward revisions. The standard deviation of the revisions, like their mean, is very similar across countries, with perhaps New Zealand having the most volatile revisions. All series feature a negative skewness, and a substantial kurtosis. Thus, large negative revisions are not uncommon. Given the sample available for our analysis, which includes the largest global recession since the Great Depression, this summary statistic is perhaps not that surprising.

Panel B in Table 1 reports the cross-country correlations between the revision series. ${ }^{7}$ All correlations are higher than 0.60, and between New Zealand and Sweden it is as high

\footnotetext{
${ }^{5}$ Here for simplicity we assume that all central banks produce these forecasts at regular interval four times year; however, in practice, the frequency of publications varies among the central banks as explained in greater detail in Appendix A.

${ }^{6}$ Here, the mean one-step ahead revision, or forecast error, for the three central banks considered is just -0.06 , -0.01, and -0.05 for New Zealand, Norway, and Sweden, respectively. Moreover, the standard deviation in these series is only between 0.10 and 0.36 .

${ }^{7}$ In panel B the sample available for Sweden is used.
} 
Table 1. Summary statistics. Panel A reports the first four moments of the revision series (using the convention where the normal distribution has a kurtosis equal to 3). Panel B reports the cross-country correlations between the revision series. Panel C reports parameters from estimating an autoregressive model. Standard errors are reported in parentheses. *,**, and ${ }^{* * *}$, indicate that coefficients are statistically significant at the $10 \%, 5 \%$, and $1 \%$ level, respectively. Test statistics are computed using a residual bootstrap.

Panel A: Moments

\begin{tabular}{|c|c|c|c|c|c|c|c|c|c|}
\hline & \multicolumn{3}{|c|}{ New Zealand } & \multicolumn{3}{|c|}{ Norway } & \multicolumn{3}{|c|}{ Sweden } \\
\hline & $r_{12, t+1}$ & $r_{23, t+1}$ & $r_{34, t+1}$ & $r_{12, t+1}$ & $r_{23, t+1}$ & $r_{34, t+1}$ & $r_{12, t+1}$ & $r_{23, t+1}$ & $r_{34, t+1}$ \\
\hline Mean & -0.13 & -0.14 & -0.13 & -0.10 & -0.14 & -0.16 & -0.15 & -0.19 & -0.20 \\
\hline Std. & 0.50 & 0.60 & 0.62 & 0.37 & 0.47 & 0.54 & 0.40 & 0.49 & 0.54 \\
\hline Skew & -2.06 & -1.62 & -1.38 & -3.09 & -2.26 & -1.88 & -1.90 & -1.43 & -1.19 \\
\hline Kurt. & 8.81 & 6.52 & 5.71 & 13.40 & 8.65 & 6.54 & 6.78 & 5.17 & 4.46 \\
\hline
\end{tabular}

Panel B: Correlations

\begin{tabular}{|c|c|c|c|c|c|c|c|c|c|}
\hline & \multicolumn{2}{|c|}{$r_{12, t+1}$} & \multicolumn{3}{|c|}{$r_{23, t+1}$} & & \multicolumn{2}{|c|}{$r_{34, t+1}$} \\
\hline & & Norway & Sweden & & Norway & Sweden & & Norway & Sweden \\
\hline \multicolumn{2}{|c|}{ New Zealand } & 0.73 & 0.86 & & 0.66 & 0.76 & & 0.76 & 0.60 \\
\hline \multicolumn{2}{|c|}{ Norway } & & 0.80 & & & 0.75 & & & 0.77 \\
\hline \multicolumn{10}{|c|}{ Panel C: Autoregressive parameter } \\
\hline & \multicolumn{3}{|c|}{ New Zealand } & \multicolumn{3}{|c|}{ Norway } & \multicolumn{3}{|c|}{ Sweden } \\
\hline & $r_{12, t+1}$ & $r_{23, t+1}$ & $r_{34, t+1}$ & $r_{12, t+1}$ & $r_{23, t+1}$ & $r_{34, t+1}$ & $r_{12, t+1}$ & $r_{23, t+1}$ & $r_{34, t+1}$ \\
\hline$\gamma_{i j}$ & $\begin{array}{c}0.42^{* * *} \\
(0.11)\end{array}$ & $\begin{array}{c}0.40^{* * *} \\
(0.12)\end{array}$ & $\begin{array}{c}0.40^{* * *} \\
(0.12)\end{array}$ & $\begin{array}{c}0.47^{* *} \\
(0.16)\end{array}$ & $\begin{array}{c}0.45^{* *} \\
(0.16)\end{array}$ & $\begin{array}{l}0.30^{*} \\
(0.18)\end{array}$ & $\begin{array}{c}0.51^{* * *} \\
(0.15)\end{array}$ & $\begin{array}{c}0.38^{* *} \\
(0.16)\end{array}$ & $\begin{array}{c}0.35^{* *} \\
(0.17)\end{array}$ \\
\hline$R_{a d j}^{2}$ & 0.16 & 0.15 & 0.14 & 0.20 & 0.18 & 0.06 & 0.24 & 0.12 & 0.10 \\
\hline $\mathrm{N}$ & 65 & 64 & 63 & 33 & 32 & 31 & 33 & 32 & 31 \\
\hline
\end{tabular}

as 0.86 for the revisions between the one and two-step ahead forecasts. These high cross country correlations indicate that there might be some common forces behind the interest rate forecast revisions, a theme we will come back to below.

Finally, the statistics reported in Panel $\mathrm{C}$ of Table 1 show how persistent the forecast revisions are. The results are obtained by estimating simple univariate autoregressive models of order one, $\mathrm{AR}(1)$, and reveal that there are statistically significant evidence of autocorrelation in all countries, (with the possible exception of $r_{34, t+1}$ for Norway). ${ }^{8}$ Hence, there is predictability in the interest rate forecast revisions. Note, however, that ${ }^{8}$ We have used various information criteria to determine the lag lengths, finding that an $\operatorname{AR}(1)$ in most cases is the preferred specification. For simplicity, and to make the results compatible across horizons and countries, we use this specification for country and horizon comparisons. 
the explanatory power is weak, as the $R^{2}$ is typically small. We also observe from the last row of the table that there are relatively few time series observations available for the Norwegian and Swedish samples, but considerably more data to work with for New Zealand. This follows naturally, since the Reserve Bank of New Zealand was also the first central bank to start publishing own forecasts of the interest rates.

\section{$3 \quad$ Predicting Forecast Revisions}

Having established that the interest rate forecast revisions are autocorrelated, the interesting question is then; can we predict these revisions using other information that was available to the policy makers at the time of making their initial prediction? To answer this question we use various domestic and international indicators, and test if they add marginal predictive power for the interest rate forecast revisions. Our goal is to inspect whether the central banks efficiently use all available information when making their forecast. If this is true we should not expect to find any significant relationship between our candidate indicators and the forecast revisions. If, on the other hand a central bank gradually incorporates this initial information by systematically adjusting the forecast as time goes by, we would expect to see a statistically significant relationship between certain indicators and the forecast revisions.

More formally, we run a number of simple autoregressive distributed lag (ADL) models:

$$
r_{i j, t+1}=\alpha_{i j, n}+\gamma_{i j, n} r_{i j, t}+\beta_{i j, n} x_{n, t+1-j}+\varepsilon_{i j, t+1} .
$$

where $x_{n, t+1-j}$ stands for indicator $n$, with $n=1, \ldots, N$, observed at time $t+1-j$, and $r_{i j, t+1}$ is the forecast revisions as defined in the previous section. As emphasized, key to the analysis is the fact that we only include information which was available to the central banks when they made their first release of the interest rate projections, as reflected by the $t+1-j$ indexation for the indicators $x_{n}$. Based on the results obtained from the simple AR regressions, reported in Table 1, only one lag of the forecast revision itself is included in the model.

Our set of explanatory variables consists of various global and domestics indicators. Table 5 in Appendix A provides a full description. We note here that all of the indicators are available in real-time, are not subsequently revised, and could have been part of the central banks's information set when making their initial forecasts. To capture what we label as the fundamental part of central banks's information set, we include consumer prices and industrial production. We also include a set of forward looking variables, such 
as the term structure spread (an indicator of the future stance of monetary policy), the stock return index (reflecting the general sentiment of investors), consumer confidence indicator (which is a proxy of consumer expectation about future economic conditions), as well as various money market rates and exchange rates. ${ }^{9}$ For all of these variables, we include in our dataset (when possible) both the domestic and the foreign counterparts, where the latter group consists of one common global country (the US) and one or two regional trading partners; for New Zealand the region is Australia; for Norway the country/regions are Sweden and the euro area; and for Sweden the country/regions are Norway and the euro area. In addition, we also include some common global indexes, such as oil prices, a volatility index and a business cycle activity index (for the U.S.).

While the interest rate forecast revisions are quarterly variables, all of the indicators in the dataset are available at a monthly frequency. Since we record the exact date at which the initial interest rate forecast was released, cf. Section 2, this allows us to bridge the monthly information with the quarterly revisions without using more information than the policy makers actually had at the time. At the same time, we exploit the availability of the monthly data to ensure that our dataset is not stale relative to what the policymakers actually used when forming their expectations about the future. For example, if the initial central bank prediction was released in month three of quarter $t+1-j$, we use information up to month two of the same quarter when predicting the revision to the initial forecast at time $t+1$.

Prior to estimation, all variables are made stationary. Depending on the particular series, this is done by using either monthly differences, the year-on-year growth rate of the monthly variables, or by keeping the series in levels, see Table 5 in Appendix A for details. Finally, we normalize all indicators to simplify the interpretations of the regression coefficients. Not all indicators we use are available for all three countries. Thus, the number of indicators entertained $(N)$, will vary somewhat depending on the country studied (New Zealand, Norway, or Sweden).

\subsection{Global versus domestic indicators}

Figure 2 presents a summary of the ADL regression results. That is, for each country and indicator specification, we plot the coefficients on $\beta_{i j, n}$ for the three forecast horizons $r_{12}$,

\footnotetext{
${ }^{9}$ Variables such as Gross Domestic product (GDP), investment, consumption, as well as leading indicators such as the OECD's Composite Leading Indicator (CLI), are all excluded because some of the subcomponents, and then the series themselves, are subject to revisions.
} 
$r_{23}$, and $r_{34}$ as bars, from left to right. For ease of exposition, forward looking variables such as stock prices, consumer confidence indicators and spreads are ordered to the left in the figures, while fundamental variables such as industrial production and CPI are ordered to the right. Grey and black bar color shadings are used to indicate when coefficients are statistically significant at the $10 \%$ and $5 \%$ level, respectively. As the various indicators are standardized prior to estimation, the height of the bars is indicative of the relative strength of the relationships.

The results suggest a systematic role for typical forward looking variables in predicting the revisions to the projected policy rate path. That is, for New Zealand, Norway and Sweden, the consumer confidence index, stock returns and business cycle indicators are often significant in the predictive regressions. Furthermore, in unreported results we confirm that the autocorrelation coefficient is generally no longer significant when these variables are included in each of the regressions, and the $R^{2}$ increases substantially relatively to the pure autoregressive specification reported in Table 1. Together these findings suggest that the systematic pattern in the revisions of the policy rate is well captured by these indicators.

Turning now to the fundamental variables typically included in a central bank's policy rule, i.e., foreign and domestic inflation, industrial production (as a proxy for GDP), exchange rates and foreign interest rates, we find fewer of these to be significant in the predictive regressions. It is particularly interesting that almost none of the various interest rate measures seem to be able to explain the forecast revisions. The exceptions are various inflation measures, which tend to have strong predictive power irrespective of whether they are international or not.

In New Zealand and Sweden, the best performing indicator, at least on the shortest horizon, is the US FED variable, which is a business cycle measure for the U.S. economy. Thus, international business cycles matter not only for economic developments in small open economies, but also for the revision of forecasts made by the central banks in these economies. In Norway, the most important variable is the oil price (potentially together with foreign inflation). This finding speaks directly to studies that have documented the considerable importance of oil for the Norwegian economy, see in particular Bjørnland and Thorsrud (2015). 
New Zealand

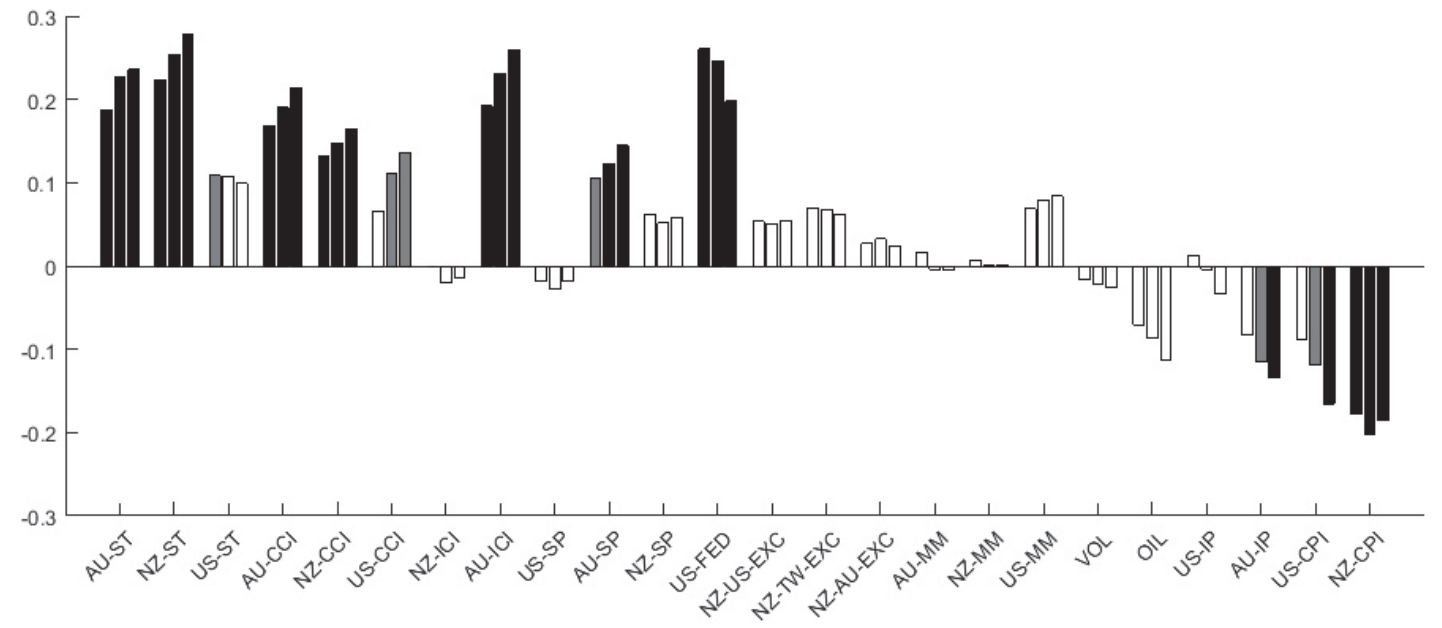

Norway

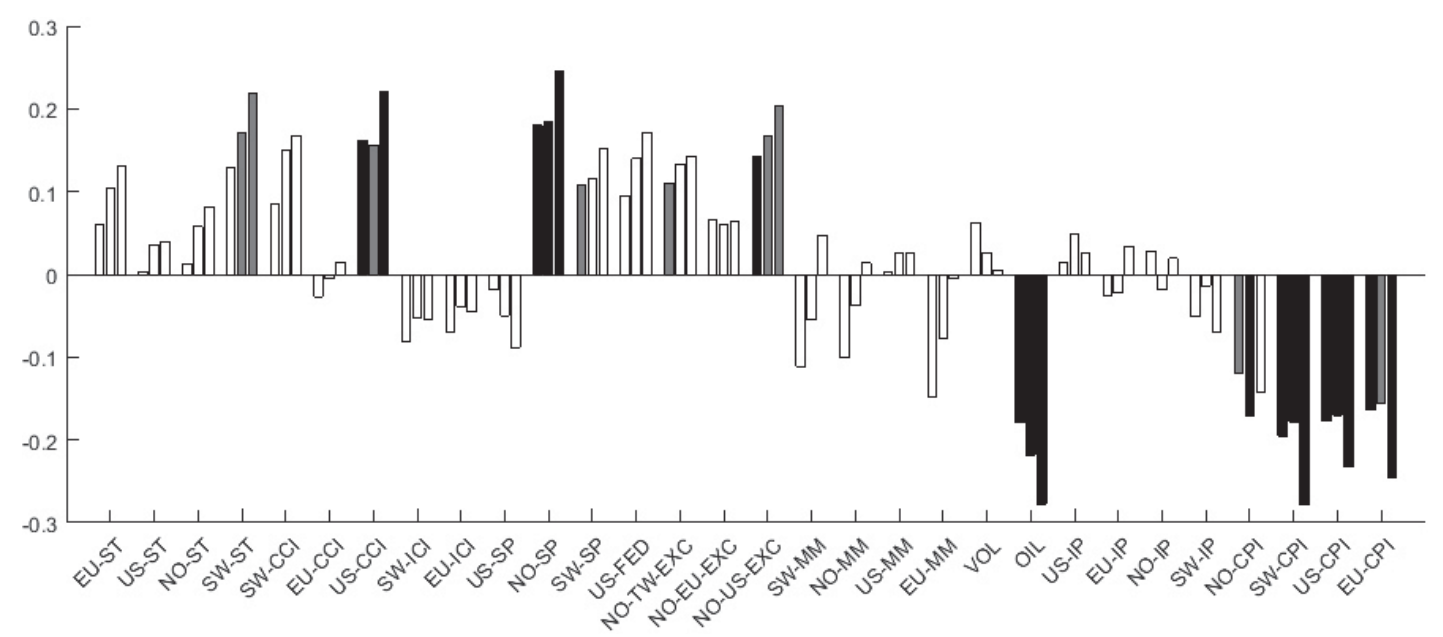

Sweden

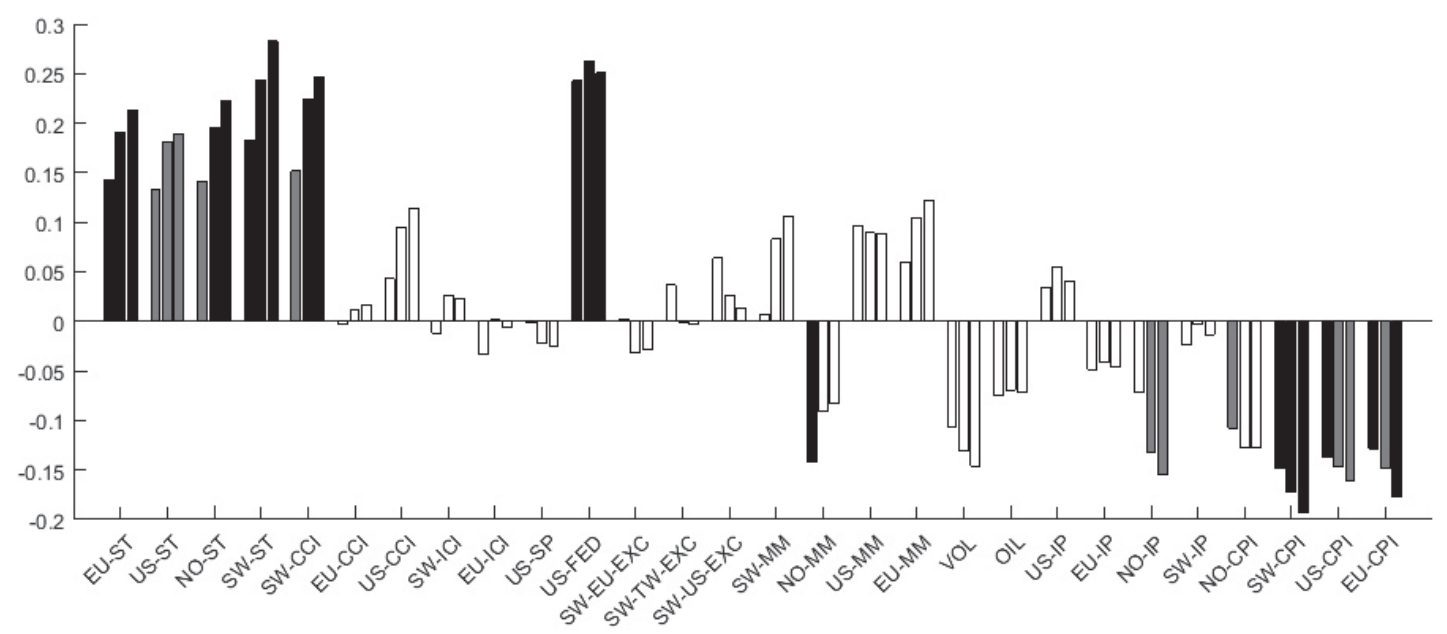

Figure 2. Forecast revisions and ADL regression results. The figures report the coefficients on $\beta_{i j, n}$ from equation 3 for each indicator and for all the three forecast horizons $r_{12}, r_{23}$, and $r_{34}$ (from left to right). The gray and black bar color shadings indicate that coefficients are statistically significant at the $10 \%$ and $5 \%$ level, respectively. No shading (white) indicates not significant. Test statistics are computed using a residual bootstrap. See Table 5 in Appendix A for a definition of the variable abbreviations. 


\subsection{Global versus domestic factors}

Although the findings from the previous section document a large degree of predictability, many of the indicators seem equally useful for predicting the interest rate revisions. However, evaluating the indicators separately may not seem all that useful. Central banks do not typically look at only one single indicator when making their interest rate decisions, but filter large information sets. Furthermore, for some indicators it is not always clear whether it is the domestic or the international counterpart that adds the most predictive power. For instance, for New Zealand, both the Australian and the domestic stock price indexes are significant in the predictive regressions. Yet, this should come as no surprise. Typically, there is a common component in the foreign and the domestic counterpart of forward looking series, implying that they move in the same direction over the sample. This could, for instance, be due to financial integration. In particular, as agents can diversify their risk by investing in different markets, financial prices will become more synchronized through arbitrage.

To address these issues we first separate the information set used for each country into an international and domestic part, where each block of data only contains those indicators that individually added significant marginal predictive power in the regression conducted in Section 3.1. We then summarize the informational content in each dataset (foreign and domestic) by estimating factors using principal components analysis (PCA). ${ }^{10}$ After estimating the two factors, one foreign and one domestic, we include both in an extended ADL specification, and evaluate which of the two contributes the most in explaining the forecast revisions.

Summarizing the information in each data set using factor estimates has many advantages. First, as demonstrated in a number of studies, and perhaps most prominently in Bernanke et al. (2005), using factor analytical techniques can improve our understanding of the monetary policy transmission mechanism. Second, summarizing the informational content in large data sets using common factors tend to perform well in forecasting settings, see, e.g., Stock and Watson (2002), Giannone et al. (2008), and Bjørnland et al.

${ }^{10} \overline{\mathrm{As} \text { documented by, e.g., Boivin and } \mathrm{Ng}}$ (2003), more information is not necessarily better when predicting using principal components. Hence, when constructing the datasets prior to PCA estimation, we include only variables that are individually significant at the 10 percent level, which amounts to roughly half the variables, cf. Figure 2. The PCA estimator used is standard. Let $X$ be a $T \times N$ matrix containing either the international or domestic variables, $\Lambda$ the factor loadings, and $F$ the factor. The factor estimates are then found by solving the following problem: $\min _{F, \Lambda} V(\Lambda, F)$ s.t. $N^{-1} \Lambda^{\prime} \Lambda=$ $I$ and $\Sigma_{F}$ diagonal, where $V(\Lambda, F)=\frac{1}{N T} \sum_{t=1}^{T}\left(X_{t}-\Lambda F_{t}\right)^{\prime}\left(X_{t}-\Lambda F_{t}\right)$. 
Table 2. Forecast Revisions and factor predictability. Panel A reports the results when only variables significant at the $10 \%$ level, cf. Figure 2, are used to construct the respective factors. Panel B reports the results when the factors used are made orthogonal to each other. Standard errors are reported in parentheses. $* * *$, and $* * *$, indicate that coefficients are statistically significant at the $10 \%, 5 \%$, and $1 \%$ level, respectively. Test statistics are computed using a residual bootstrap.

\begin{tabular}{|c|c|c|c|c|c|c|}
\hline & \multicolumn{2}{|c|}{ New Zealand } & \multicolumn{2}{|c|}{ Norway } & \multicolumn{2}{|c|}{ Sweden } \\
\hline & $r_{12, t+1}$ & $r_{34, t+1}$ & $r_{12, t+1}$ & $r_{34, t+1}$ & $r_{12, t+1}$ & $r_{34, t+1}$ \\
\hline \multicolumn{7}{|c|}{ Panel A: $10 \%$ significant level } \\
\hline$\gamma_{0}$ & $\begin{array}{l}-0.03 \\
(0.15)\end{array}$ & $\begin{array}{l}-0.08 \\
(0.16)\end{array}$ & $\begin{array}{l}0.30 * \\
(0.16)\end{array}$ & $\begin{array}{c}0.20 \\
(0.17)\end{array}$ & $\begin{array}{c}0.14 \\
(0.19)\end{array}$ & $\begin{array}{l}-0.00 \\
(0.19)\end{array}$ \\
\hline$\beta^{I}$ & $\begin{array}{l}0.21^{*} \\
(0.11)\end{array}$ & $\begin{array}{c}0.27^{* *} \\
(0.14)\end{array}$ & $\begin{array}{c}0.27^{* *} \\
(0.10)\end{array}$ & $\begin{array}{l}0.28^{*} \\
(0.17)\end{array}$ & $\begin{array}{c}0.03 \\
(0.11)\end{array}$ & $\begin{array}{l}-0.04 \\
(0.16)\end{array}$ \\
\hline$\beta^{D}$ & $\begin{array}{c}0.10 \\
(0.09)\end{array}$ & $\begin{array}{c}0.13 \\
(0.11)\end{array}$ & $\begin{array}{l}-0.09 \\
(0.10)\end{array}$ & $\begin{array}{l}-0.00 \\
(0.16)\end{array}$ & $\begin{array}{l}0.20^{*} \\
(0.10)\end{array}$ & $\begin{array}{c}0.36^{* *} \\
(0.15)\end{array}$ \\
\hline$R_{a d j}^{2}$ & 0.34 & 0.32 & 0.43 & 0.27 & 0.41 & 0.33 \\
\hline $\mathrm{N}$ & 65 & 63 & 33 & 31 & 33 & 31 \\
\hline \multicolumn{7}{|c|}{ Panel B: $10 \%$ significant level and orthogonal factors } \\
\hline$\gamma_{0}$ & $\begin{array}{c}-0.03 \\
(0.15)\end{array}$ & $\begin{array}{l}-0.08 \\
(0.16)\end{array}$ & $\begin{array}{c}0.30^{*} \\
(0.16)\end{array}$ & $\begin{array}{c}0.20 \\
(0.17)\end{array}$ & $\begin{array}{c}0.14 \\
(0.19)\end{array}$ & $\begin{array}{l}-0.00 \\
(0.19)\end{array}$ \\
\hline$\beta^{I}$ & $\begin{array}{c}0.30 * * * \\
(0.07)\end{array}$ & $\begin{array}{c}0.37^{* * *} \\
(0.09)\end{array}$ & $\begin{array}{c}0.20^{* * *} \\
(0.05)\end{array}$ & $\begin{array}{c}0.28^{* * *} \\
(0.09)\end{array}$ & $\begin{array}{c}0.20^{* * *} \\
(0.07)\end{array}$ & $\begin{array}{c}0.26^{* * *} \\
(0.10)\end{array}$ \\
\hline$\beta^{D}$ & $\begin{array}{c}0.10 \\
(0.09)\end{array}$ & $\begin{array}{c}0.13 \\
(0.11)\end{array}$ & $\begin{array}{l}-0.09 \\
(0.10)\end{array}$ & $\begin{array}{c}-0.00 \\
(0.16)\end{array}$ & $\begin{array}{c}0.20^{*} \\
(0.10)\end{array}$ & $\begin{array}{c}0.36^{* *} \\
(0.15)\end{array}$ \\
\hline$R_{a d j}^{2}$ & 0.34 & 0.32 & 0.43 & 0.27 & 0.41 & 0.33 \\
\hline $\mathrm{N}$ & 65 & 63 & 33 & 31 & 33 & 31 \\
\hline
\end{tabular}

(2015). Third, as discussed in Section 1, a large body of evidence from the international business cycle literature has found that domestic business cycles (in small open economies) are well explained by one common international and domestic factor. Lastly, by extending the ADL by two factors instead of many different (domestic and foreign) indicators we avoid running into degrees of freedom problems due to our rather limited sample availability.

Table 2 summarizes the results for the factor extended ADL results. ${ }^{11}$ The rows indexed by $\gamma_{i j}$ list the estimated autoregressive coefficients, and the rows indexed by $\beta^{I}$ $\left(\beta^{D}\right)$ lists the estimated coefficients associated with the international (domestic) factor. Panel A shows that the international factor contributes significantly to the predictive

${ }^{11}$ For readability, the $r_{23, t+1}$ horizons are excluded from the table. The results from this horizon, across countries, are qualitatively the same as for those reported and can be obtained on request. 
regressions. For both New Zealand and Norway the domestic factor is insignificant, while the international factor is significant at the $10 \%$ level. In Sweden, however, it is the domestic factor that seems to be the most important one.

Panel B in Table 2 reports the results from the factor extended ADL estimations when one additional extension has been implemented when extracting the factors. As stressed above, there is likely a very high correlation between many of the (forward looking) domestic and international variables used to estimate foreign and domestic factors and, as pointed out by Reichlin (2010), this might be the case because of the occurrence of general equilibrium effects in highly integrated markets. Here, ignoring this issue might lead to problems of multicollinearity when estimating the ADL specification, and might also blur the interpretation of the estimated coefficients. We therefore implement a factor rotation prior to estimating the ADL specification. Following common practice, see, e.g., Gregory et al. (1997), Kose et al. (2003) and Thorsrud (2013), this is done under the assumption that any movements in the domestic factor that are not explained by the international factor must be purely due to domestic forces, and implemented by estimating the following equation: $F_{t}^{D}=\beta F_{t}^{I}+e_{t}$. Here, $F_{t}^{D}$ and $F_{t}^{I}$ are the estimated factors from the domestic and foreign data sets, containing variables that individually had a significant predictive power in explaining the forecast revisions (i.e., the factors used in Panel A in Table 2.). Letting the estimated residual $\hat{e}_{t}=\tilde{F}_{t}^{D}$, delivers a new domestic factor that is orthogonal to the international one.

As seen from the results reported in Panel B in Table 2, this additional factor rotation increases the statistical importance of the foreign factors in all countries. In fact, the foreign factor is now always significant even at the $1 \%$ level. In neither New Zealand nor Norway does the purely domestic factor contribute significantly to the model fit. In Sweden, the domestic factors are still significant, but not as strongly as the international factor.

We conclude from this analysis that most of the predictability of the central banks' interest rate revisions are due to inefficient incorporation of international developments. Had the central banks' used the international information set available to them in realtime, a large chunk of the forecast revisions, and thus errors, could have been avoided.

\subsection{GDP and inflation}

Our focus so far has been on investigating whether or not forecast revisions of the interest rate paths published by central banks are predictable. However, to the extent that the 


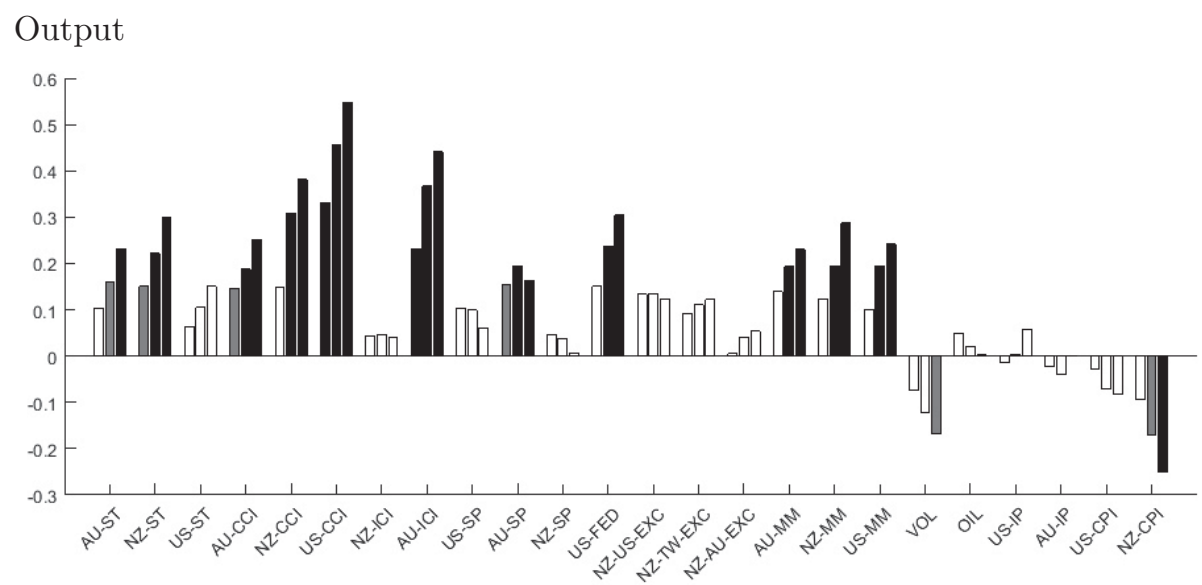

Inflation

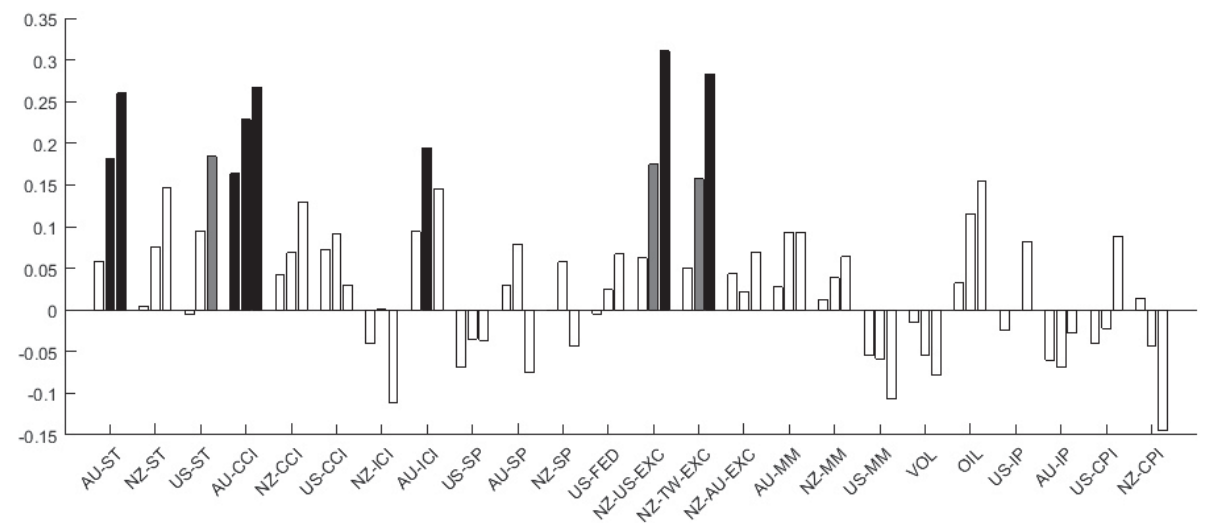

Figure 3. Forecast revisions of inflation and output and ADL regression results in New Zealand. See Figure 2 for further explanations.

central banks revise their forecasts of inflation and output in a coherent manner relative to the interest rate, one would expect that also these revisions are predictable using the same information sets as when predicting interest rate forecast revisions.

To investigate this issue we construct revisions series for inflation and output in the same manner as for the interest rate, and redo the analysis described in Sections 3.1 and 3.2 using either output or inflation as the dependent variable. The choice of variables/transformations reflects what the central banks themselves publish. The central banks in New Zealand and Sweden predict annualized GDP growth, while the central bank in Norway predicts the output gap. For all three countries, the banks predict yearon-year CPI inflation.

The results from this additional experiment yield two main findings. First, many of the indicators that explained the interest rate revisions also explain the revisions in GDP and inflation, see Figure 3 for New Zealand and Table 3 for summary statistics for all three 
Table 3. Spearman's rank correlation coefficients. Each entry in the table reports the correlation between the estimated $\beta_{i j}$ coefficients from the ADL regressions when the dependent variable is the interest rate revisions or the inflation (output) revisions. *,**, and ***, indicate that coefficients are statistically significant at the $10 \%, 5 \%$, and $1 \%$ level, respectively.

\begin{tabular}{|c|c|c|c|c|c|c|c|c|c|}
\hline & \multicolumn{3}{|c|}{ New Zealand } & \multicolumn{3}{|c|}{ Norway } & \multicolumn{3}{|c|}{ Sweden } \\
\hline & $\beta_{12}$ & $\beta_{23}$ & $\beta_{34}$ & $\beta_{12}$ & $\beta_{23}$ & $\beta_{34}$ & $\beta_{12}$ & $\beta_{23}$ & $\beta_{34}$ \\
\hline Inflation & $0.47^{* *}$ & $0.57^{* * *}$ & $0.40^{* *}$ & -0.04 & -0.16 & -0.11 & $0.69 * * *$ & $0.82^{* * *}$ & $0.81^{* * *}$ \\
\hline Output & $0.73^{* * *}$ & $0.80^{* * *}$ & $0.84^{* * *}$ & 0.00 & 0.22 & $0.55^{* * *}$ & $0.63^{* * *}$ & $0.86^{* * *}$ & $0.66^{* * *}$ \\
\hline
\end{tabular}

countries. ${ }^{12}$ In particular, the table shows that the correlation between the indicators that explain well interest rate forecast revisions and those that explain inflation and output is very high and significant. Especially for inflation and output in Sweden and New Zealand, we find very robust relationships. In Norway, however, the correlations are substantially lower, and most of the time not significant.

Second, as shown in Tables 8 and 9 in Appendix B, when summarizing the information sets using international and domestic factors, it is the international factors that dominate in terms of explaining the inflation and output forecast revisions, although the results are less strong compared with those for the interest rate revisions. ${ }^{13}$

Thus, for all countries we confirm the main finding from our earlier analysis, namely that it is the informational content in international variables that can explain most of the predictability in the central banks' forecast revisions. In addition, at least for New Zealand and Sweden, there seems to be a close correspondence between the information sets explaining inflation and output revisions relative to the interest rate revisions.

\section{Revision predictability and monetary policy shocks}

What consequences do the findings documented about predictability have for the conduct of monetary policy, and monetary policy shocks in particular? After all, central banks publish their interest forecasts to guide public expectations about the macro economy in general and monetary policy in particular. Hence, if the policy makers revise their

${ }^{12} \overline{\mathrm{In}}$ the interest of preserving space, the figures for the other countries are displayed in Figures 5 and 6 in Appendix B.

${ }^{13}$ Note here that for some country and horizon combinations, neither international nor domestic indicators were significant at the $10 \%$ level. To alleviate this issue we first included all variables when constructing the orthogonal factors, and then, as when predicting interest rate forecast revisions, only the variables that were significant at $10 \%$ level. This latter specification results in some missing observations. 
forecast due to, say, an inefficient response to international economic developments in the past, this might create a surprise move in the interest rate, i.e., a monetary policy shock, that potentially was unintended. However, if market participants already at the forecast origin know that the central bank would eventually have to revise their predictions, i.e., they anticipate the deviations of what the policy maker said she would do and what she actually ends up doing, then these forecast revisions should not move the market. The information should already be fully incorporated in the market rates.

What should we expect? Using the results from the analysis in Section 3 a reasonable expectation is that that market participants do not anticipate the interest rate revisions. After all, we showed that money market rates did not add any value added in predicting the revisions to the policy rate, suggesting they do not contain independent information about policy revisions. A similar view is obtained if one looks at simple correlations between revisions in the policy rate and contemporaneous changes in money market rates. For example, the correlations between the $r_{12, t+1}$ forecast revisions and the quarterly change in various market interest rate measures are strong, positive, and generally significant in all three countries, see Table 10 in Appendix B. Of course, these correlations might not necessarily be due to the central banks lack of timely response to foreign shocks, but rather new information arriving after the forecast origin.

To investigate the implications of policy makers acting on their apparent mistakes (their forecast errors) more formally, we specify a standard monetary vector autoregression (VAR):

$$
A(L) y_{t}=\eta_{t}
$$

where an intercept is dropped for notational simplicity. The $n \times 1$ vector $y_{t}$ includes the output gap, inflation, the real exchange rate, stock prices, and the change in the market interest rate, and Appendix A.2 provides a more detailed description about how the data are collected and transformed. To answer the question of interest, instead of identifying a monetary policy shock using standard structural VAR methods, see e.g. Christiano et al. (1999), Eichenbaum and Evans (1995) and Bjørnland (2009), we use an external instrument variable (IV) approach, where the instruments are constructed from the part of the actual forecast errors that can be predicted/explained by foreign indicators.

\subsection{IV identification}

The use of instrument variables (IV) to identify shocks in a VAR was introduced by Stock (2008), and have later been used in, e.g., Stock and Watson (2012), Mertens and Ravn 
(2013), and Gertler and Karadi (2015). As in conventional structural VAR analysis, the object of interest is the structural shocks $\epsilon_{t}$, and its dynamic responses. These objects can be recovered from the reduced form residuals $\eta_{t}$ through:

$$
\eta_{t}=H \epsilon_{t}
$$

where $H$ is the structural impact matrix, and the structural shocks are assumed to be uncorrelated. The challenge for all studies is then to find a plausible identification scheme to recover $H$ and $\epsilon_{t}$. When the interest is single shock identification, the general idea with the method proposed by Stock (2008) is to use an exogenous instrument, $Z_{t}$, to achieve this. ${ }^{14}$

Assume without loss of generality that the market interest rate is ordered first in the VAR system, and let $\epsilon_{M P, t}$ denote the structural shock of interest. Then, as with standard IV estimation, two important assumptions need to be fulfilled for valid identification, namely the well known relevance and exogeneity assumptions:

$$
\begin{gathered}
E\left(\epsilon_{M P, t} Z_{t}^{\prime}\right)=\alpha^{\prime} \neq 0 \\
E\left(\epsilon_{j, t} Z_{t}^{\prime}\right)=0, j=2, \ldots, n
\end{gathered}
$$

Following the notation in Stock and Watson (2016), and assuming that the instrument used is valid, i.e., that (6) and (7) hold, the estimator of the relevant part of $H$ can be obtained by combining (5)-(7) such that:

$$
\left[\begin{array}{c}
E\left(\eta_{1, t} Z_{t}^{\prime}\right) \\
E\left(\eta_{\bullet, t} Z_{t}^{\prime}\right)
\end{array}\right]=\left[\begin{array}{ll}
H_{11} & H_{1} \\
H_{\bullet 1} & H_{\bullet \bullet}
\end{array}\right]\left[\begin{array}{c}
E\left(\epsilon_{M P, t} Z_{t}^{\prime}\right) \\
E\left(\epsilon_{\bullet} Z_{t}^{\prime}\right)
\end{array}\right]=\left[\begin{array}{c}
\alpha^{\prime} \\
H_{\bullet 1} \alpha^{\prime}
\end{array}\right]
$$

where $H_{11}$ and $H_{\bullet 1}$ are the first and subsequent elements in the first column of $H$ respectively, and $\eta_{\bullet, t}$ the remaining $n-1$ elements of $\eta_{t}$. The last equality uses an unit effect normalization imposed, $H_{11}=1$, together with (6) and (7).

Then, from the first and last term in (8) we obtain the IV estimator:

$$
H_{\bullet 1}=\frac{E\left(\eta_{\bullet}, t Z_{t}\right)}{E\left(\eta_{1, t} Z_{t}\right)}
$$

from which dynamic responses (impulse responses) can be computed using standard methods.

\footnotetext{
${ }^{14}$ Note here that the instrument is called external because it is not included in the VAR, and that although more than one instrument can be used, we restrict ourselves to only one in this analysis. See Stock and Watson (2016) for an overview of the methodology, and further references.
} 
As already stated, we use the part of the actual forecast errors that can be explained by foreign variables as an external instrument. ${ }^{15}$ Is this a good instrument? Equation (6) can be tested, and we do so below in the next section. Essentially, if the instrument is weak, it likely means that the predictable part of the forecast error does not move the market because the agents in the economy know about the forecast errors the central banks tend to make and incorporate that information efficiently. On the other hand, if the predictable part of the forecast error is a strong instrument for the monetary policy error, it will be a valid instrument and identify a "conventional" monetary policy shock.

Equation (7) can not be tested. Still, as our instrument variable, $Z_{t}$, is the predictable part of the forecast error, it is very likely that it is fulfilled. Recall that to predict the forecast errors we used information that was available to the policy maker at least two quarters prior to the forecast horizon. Is seems unlikely that this information set should be correlated with future values of the structural VAR shocks (other than the structural monetary policy shock). In contrast, if we had used the unexplained part of the forecast errors from the predictive regressions as an instrument, it would potentially have included all new information arriving between the forecast origin and horizon, and therefore also potentially been correlated with the other structural VAR shocks. A similar argument applies against using the whole forecast error, since this measure then likely includes both an exogenous and endogenous part.

Given our framework, we believe the IV approach has three advantages compared with more traditional identification schemes used to identify a (potential) monetary policy shock: First, we do not need to take a stand on any timing assumptions. For example, in many empirical studies, output and inflation are typically restricted from responding on impact to unexpected changes in the interest rate. Using the IV approach, all variables are allowed, but not restricted to, respond contemporaneously to the shock of interest, see equation (9). Second, compared with studies that typically include the forecast errors as a direct measure of the shock of interest directly into the VAR, i.e., Kuttner (2001), Hamilton (2003), and Romer and Romer (2004), we do not have to assume that this measure captures the entirety of the structural shock. As argued in Stock and Watson

${ }^{15}$ There is, as shown in equation (2), a close connection between the forecast errors and revisions. This connection is confirmed when we redo the analysis from Section 3.2, using the actual forecast errors instead of the revisions, see Table 7 in Appendix B. We focus on the forecast errors here because they capture the sum of revisions, i.e., a larger part of the central bank's updates. We have, however, also done the analysis using the predictable part of the forecast revisions as instruments. Qualitatively, the results shown in Figures 4 and 8 below are similar, but the instruments are weaker. 
(2016), such an assumption can be questionable, lead to errors-in-variables biases, but be alleviated through the use of IV identification. Third, and on a more practical note, we do not have a long enough sample to include the forecast errors directly into the VAR system. However, by using the IV identification scheme, $H$ can be estimated on a sub-sample, for which the forecast errors are available, relative to the sample the VAR is estimated on.

\subsection{VAR estimation and instrument validity}

The VAR model in (4) is estimated for each of the three economies already considered; New Zealand, Norway, and Sweden. For New Zealand we let the estimation period start in 1997. For Norway and Sweden we start in 1999. These dates correspond to time periods where all three countries had either adopted inflation targeting, or were about to do so. For all three countries we end the estimation sample in $2014 .{ }^{16}$

For each country we consider six different VAR specifications. In particular, we estimate the VARs using three different market interest rates. As discussed in Gertler and Karadi (2015), because we wish to include shocks to forward guidance in the measure of the policy innovation, we use a policy indicator with a longer maturity than the shortterm rates to identify a monetary policy shock. Accordingly, we estimate the VAR using either the three month money market rate, or two measures of longer-term government bond yields. ${ }^{17}$

For each country we also consider two different instruments. The first set of instruments is constructed by choosing the best performing single indicator in terms of predicting the forecast revisions, cf. Section 3.1. For New Zealand and Sweden, the indicator used is the US FED variable, while it is the $O I L$ variable for Norway. The second set of instruments is constructed by using the orthogonal factors derived in Section 3.2. For both sets of instruments we use the fitted values from predicting the forecast error at the two-step ahead horizon. We discuss this choice further in Appendix B.1.

Table 4 reports the results of regressing the various VAR interest rate residuals on the two proposed instruments. With the exception of New Zealand, for most instrument and

${ }^{16}$ The lag lengths used in the VAR are determined by the AIC information criterion, and suggest that either 1 or 2 lags are appropriate. Parameter uncertainty is simulated using a residual bootstrap.

${ }^{17}$ The exact maturities and type of instruments we use varies somewhat between the countries due to data availability. For New Zealand we use the 90-day bank bill yield, and the 1 and 5 year secondary market government bond yields. For Norway we use the 3 month-NIBOR, and 3 and 5-year government bond yields. For Sweden, we use the 3 month STIBOR, and 2 and 5 -year government bond yields. All statistics are collected from the Reserve Bank of New Zealand, Norges Bank and Sveriges Riksbank, respectively. 
Table 4. First stage TSLS regressions. The results are obtained by estimating the various money market rate VAR residuals on the instrument. In Panel A the instruments are constructed by choosing the best performing single indicator in terms of predicting the central bank's forecast revisions. In Panel B the instruments are constructed using the orthogonal factors derived in Section 3.2. For both sets of instruments we use the fitted values from predicting the forecast error at the two-step ahead horizon.

\begin{tabular}{|c|c|c|c|c|c|c|c|c|c|}
\hline & \multicolumn{3}{|c|}{ New Zealand } & \multicolumn{3}{|c|}{ Norway } & \multicolumn{3}{|c|}{ Sweden } \\
\hline & 3 month & 1 year & 2 year & 3 month & 3 year & 5 year & 3 month & 2 year & 5 year \\
\hline \multicolumn{10}{|c|}{ Panel A: Single Indicator } \\
\hline F-stat & 3.37 & 7.87 & 5.74 & 0.70 & 2.93 & 1.84 & 1.74 & 0.00 & 0.84 \\
\hline$R^{2}$ & 0.06 & 0.13 & 0.10 & 0.02 & 0.09 & 0.06 & 0.07 & 0.00 & 0.03 \\
\hline $\mathrm{N}$ & 55 & 55 & 55 & 29 & 29 & 29 & 26 & 26 & 26 \\
\hline \multicolumn{10}{|c|}{ Panel B: Factors } \\
\hline F-stat & 0.70 & 3.27 & 3.30 & 1.14 & 2.49 & 1.43 & 3.26 & 0.21 & 0.54 \\
\hline$R^{2}$ & 0.01 & 0.06 & 0.06 & 0.04 & 0.08 & 0.05 & 0.12 & 0.01 & 0.02 \\
\hline $\mathrm{N}$ & 55 & 55 & 55 & 29 & 29 & 29 & 26 & 26 & 26 \\
\hline
\end{tabular}

interest rate combinations, the instruments appear to be rather weak. This may indicate that the agents in the economy have already incorporated the inefficiencies in the central banks interest rate projections, or might simply be a result of the rather short sample available for estimation. Still, for New Zealand, and using the single indicator instrument together with the 1-year interest rate, we obtain a F-statistic close to 8 , and a $R^{2}$ of 0.13 . Although the F-statistic is lower than the rule of thumb of 10 for a strong instrument, it is substantially higher than for the other countries. Accordingly, in discussing the impulse responses below, we will focus on the results for New Zealand derived using this particular interest rate and instrument combination. For Norway and Sweden we will use the results obtained from the instrument and interest rate combinations that delivers the highest F-statistic in Table 4.

\subsection{Impulse responses}

Figure 4 reports the impulse responses derived for New Zealand following a monetary policy shock that is normalized to increase the interest rate with one percentage point on impact. ${ }^{18}$ As seen in the figure, the output gap and inflation fall immediately, while the real exchange rate appreciates on impact, before depreciating back to equilibrium. Thus, there are no price and exchange rate puzzles, which many conventional structural VAR

${ }^{18}$ In the interest of brevity, the impulse responses of the interest rate are reported in Figure 7, in Appendix B. 

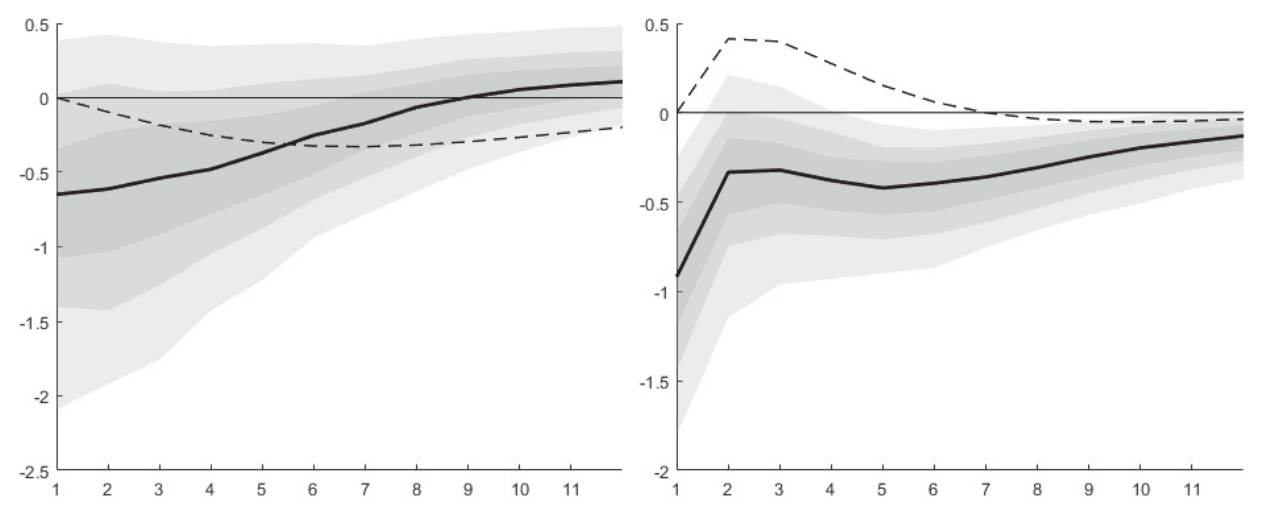

Real exchange rate

\section{Stock returns}
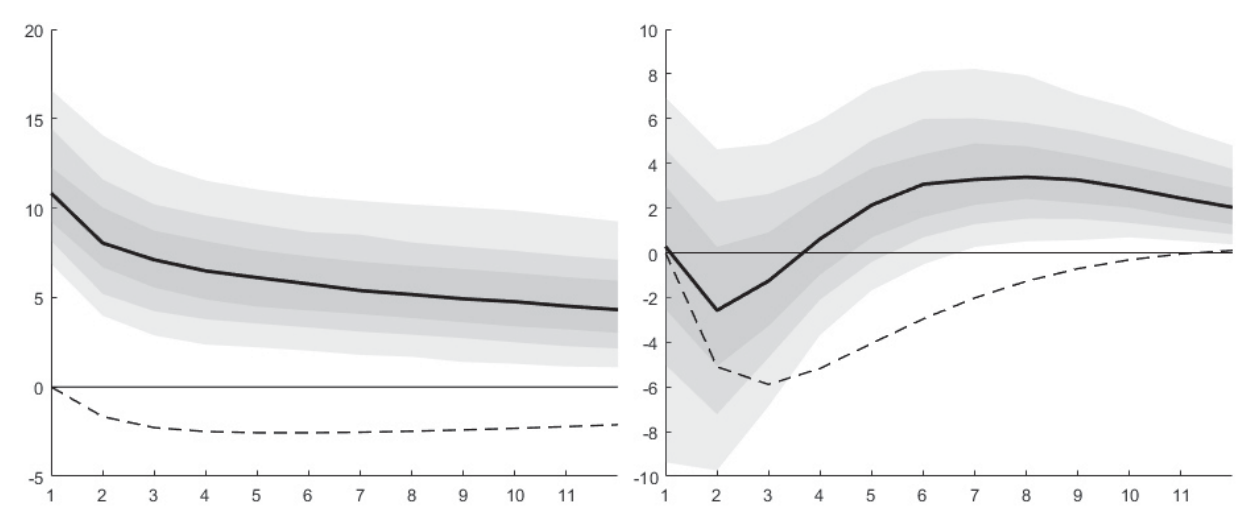

Figure 4. Impulse responses to a monetary policy shock in New Zealand. The gray shaded areas correspond to the 70, 50, and 30 percent quantiles. The black solid line is the median estimate. The black doted line is the response following a monetary policy shock identified using a recursive ordering (Cholesky identification). The x-axis reports the response horizons (in quarters). The initial shock is normalized to a $1 \%$ monetary policy tightening.

studies seem to find. In fact, when we estimate the effect of a monetary policy shock identified using a standard recursive ordering of the variables, with the interest ordered last, these puzzles become evident, see the black dotted lines in the figure. Finally, stock returns also fall as expected, but the effect is small, suggesting that the stock market may have incorporated some of the international information already.

Due to the rather weak instruments, we put less confidence in the results for Norway and Sweden than we do in the results reported for New Zealand. Still, it is interesting that we obtain largely the same responses following a monetary policy shock in these countries, see Figure 8 in Appendix B. The only somewhat puzzling results are that stock returns increase in Norway, and the output gap in Sweden initially increases, before becoming negative after roughly 5 quarters. As above, however, the monetary policy shock identified using the IV approach delivers responses more in line with theory than 
the more standard recursive identification scheme does.

Although our results are uncertain, they all point to an important lesson, namely that although the central bank's forecast errors can in part be explained by foreign indicators, they lead to surprises in the market causing economic aggregates to move more or less in line with theory. However, by responding more timely to the news, these surprises could have been avoided. Whether that would be welfare improving, and something the central banks should do, is more uncertain. There could be many reasons for why the central banks do not respond timely to global developments. In particular, inertia in monetary policy has some potential benefits, and might, for example, be optimal when policymakers are uncertain about the quantitative effects of foreign shocks (due to, e.g., modeling inefficiencies). Sticking to their announced intentions might also give policy makers more control over long-term interest rates via the expectations channel, which again can reduce financial sector instability, cf. Woodford (2003).

\subsection{Robustness}

In Appendix B.1 we show that our results are more or less robust to using other forecast horizons when constructing the instruments, and to augmenting the VAR with variables capturing foreign information. Ideally, we would also have liked to analyze how robust our results are across different sub-samples. We expect, for example, that the results could be affected by the Great Recession episode, when big revisions to the interest rate predictions occurred in all three countries, c.f., Figure 1, and (global) economic conditions changed rapidly. Still, our sample is too short to exclude this episode from estimation. Yet, the fact that our results are most pronounced in New Zealand, for which we have the longest sample, suggests that the period of the Great Recession may not be the only relevant period. On the other hand, one could also argue that it is exactly when large international shocks occur that central banks should pay particular attention to international developments.

\section{Conclusion}

We provide novel evidence that inertia in monetary policy actions is an important component of the decision-making process by policy makers in small and open economies, and that an important source explaining this inertia is a delayed monetary policy response to news about foreign variables. Furthermore, we show that the delayed responses matter 
for the dynamics of key economic and financial variables. This evidence is obtained by using the published real time interest rate projections (i.e., forward guidance) from the central banks in New Zealand, Norway and Sweden, which were the first three central banks to publish their interest rate forecasts. In particular, we run a battery of predictive regressions using domestic and foreign real-time indicators to explain interest rate forecast revisions and show that, for all three countries, there is a systematic role for international indicators in predicting the revisions to the policy rate. Most notably is the role of forward looking global indicators. In contrast, using related indexes for the domestic economy yields more or less insignificant results.

Then, to examine the implications of policy makers acting on their apparent mistakes (their forecast errors), we analyze the joint response of key economic and financial variables to the implied shocks to the policy rate using a structural VAR model. Using an external instrument approach for identification, where the instruments are constructed from the part of the forecast errors that can be predicted/explained by foreign indicators, we show that the responses to output, inflation, the exchange rate and asset returns resemble those one typically find following a monetary policy shock. 


\section{References}

Aastveit, K. A., H. C. Bjørnland, and L. A. Thorsrud (2016). The World Is Not Enough! Small Open Economies and Regional Dependence. The Scandinavian Journal of Economics 118(1), 168-195.

Backus, D., P. J. Kehoe, and F. E. Kydland (1995). International business cycles: Theory and evidence. In C. Plosser (Ed.), Frontiers of Business Cycle Research, pp. 331-257. Princeton University Press.

Baxter, M. and M. A. Kouparitsas (2005). Determinants of business cycle comovement: A robust analysis. Journal of Monetary Economics 52(1), 113-157.

Bergholt, D. and T. Sveen (2013). Sectoral interdependence and business cycle synchronization in small open economies. Mimeo, BI Norwegian Business School.

Bernanke, B., J. Boivin, and P. S. Eliasz (2005). Measuring the effects of monetary policy: A Factor-augmented Vector Autoregressive (FAVAR) approach. The Quarterly Journal of Economics 120(1), 387-422.

Bjørnland, H. C., F. Ravazzolo, and L. A. Thorsrud (2015). Forecasting GDP with global components. This time is different. International Journal of Forecasting (forthcoming).

Bjørnland, H. C. and L. A. Thorsrud (2015). Boom or gloom? Examining the Dutch disease in two-speed economies. Economic Journal (forthcoming).

Bjørnland, H. C. (2009). Monetary policy and exchange rate overshooting: Dornbusch was right after all. Journal of International Economics 79(1), 64-77.

Boivin, J. and S. Ng (2003). Are More Data Always Better for Factor Analysis? NBER Working Papers 9829, National Bureau of Economic Research, Inc.

Canova, F. and J. Marrinan (1998). Sources and propagation of international output cycles: common shocks or transmission? Journal of International Economics $46(1)$, $133-166$.

Christiano, L. J., M. Eichenbaum, and C. L. Evans (1999). Monetary policy shocks: What have we learned and to what end? In J. B. Taylor and M. Woodford (Eds.), Handbook of Macroeconomics, Volume 1 of Handbook of Macroeconomics, Chapter 2, pp. 65-148. Elsevier. 
Ciccarelli, M. and B. Mojon (2010). Global inflation. The Review of Economics and Statistics 92(3), 524-535.

Eichenbaum, M. and C. L. Evans (1995). Some empirical evidence on the effects of shocks to monetary policy on exchange rates. The Quarterly Journal of Economics 110(4), 975-1009.

Eickmeier, S. (2007). Business cycle transmission from the US to Germany - a structural factor approach. European Economic Review 51(3), 521 - 551.

Gertler, M. and P. Karadi (2015). Monetary Policy Surprises, Credit Costs, and Economic Activity. American Economic Journal: Macroeconomics 7(1), 44-76.

Giannone, D., L. Reichlin, and D. Small (2008). Nowcasting: The real-time informational content of macroeconomic data. Journal of Monetary Economics 55(4), 665-676.

Gregory, A. W., A. C. Head, and J. Raynauld (1997). Measuring World Business Cycles. International Economic Review 38(3), 677-701.

Gürkaynak, R. S., B. Sack, and E. T. Swansonc (2005). Do actions speak louder than words? the response of asset prices to monetary policy actions and statements. International Journal of Central Banking.

Hamilton, J. D. (2003). What is an oil shock? Journal of Econometrics 113(2), 363-398.

Justiniano, A. and B. Preston (2010). Can structural small open-economy models account for the influence of foreign disturbances? Journal of International Economics 81(1), $61-74$.

Kose, M. A., C. Otrok, and C. H. Whiteman (2003). International business cycles: World, region, and country-specific factors. American Economic Review 93(4), 1216-1239.

Kuttner, K. N. (2001). Monetary policy surprises and interest rates: Evidence from the fed funds futures market. Journal of Monetary Economics 47(3), 523-544.

Mertens, K. and M. O. Ravn (2013). The dynamic effects of personal and corporate income tax changes in the united states. American Economic Review 103(4), 1212-47.

Mirkov, N. and G. J. Natvik (2016). Announcements of interest rate forecasts: Do policymakers stick to them? Journal of Money, Credit and Banking 48(5). 
Monacelli, T. and L. Sala (2009). The international dimension of inflation: Evidence from disaggregated consumer price data. Journal of Money, Credit and Banking 41, $101-120$.

Moneta, F. and R. Rüffer (2009). Business cycle synchronisation in East Asia. Journal of Asian Economics 20(1), 1-12.

Mumtaz, H., S. Simonelli, and P. Surico (2011). International comovements, business cycle and inflation: A historical perspective. Review of Economic Dynamics 14(1), $176-198$.

Mumtaz, H. and P. Surico (2008). Evolving international inflation dynamics: Evidence from a time-varying dynamic factor model. Bank of England working papers 341, Bank of England.

Reichlin, L. (2010). Comment on "Global forces and monetary policy effectiveness". In J. Gali and M. Gertler (Eds.), International Dimensions of Monetary Policy, Chapter 8, pp. 478-488. University of Chicago.

Romer, C. D. and D. H. Romer (2004). A new measure of monetary shocks: Derivation and implications. American Economic Review 94(4), 1055-1084.

Rudebusch, G. D. and J. C. Williams (2008). Revealing the secrets of the temple: The value of publishing central bank interest rate projections. In Asset Prices and Monetary Policy, pp. 247-289. University of Chicago Press.

Stock, J. and M. Watson (2012). Disentangling the channels of the 2007-2009 recession. Brookings Papers on Economic Activity Spring 2012, 81-135.

Stock, J. H. (2008). What's new in econometrics: Time series, lecture 7. Short course lectures, NBER Summer Institute.

Stock, J. H. and M. W. Watson (2002). Macroeconomic forecasting using diffusion indexes. Journal of Business \& Economic Statistics 20(2), 147-62.

Stock, J. H. and M. W. Watson (2005). Understanding changes in international business cycle dynamics. Journal of the European Economic Association 3(5), 968-1006.

Stock, J. H. and M. W. Watson (2016). Factor models and structural vector autoregressions in macroeconomics. 
Swanson, E. T. (2006). Have increases in federal reserve transparency improved private sector interest rate forecasts? Journal of Money, Credit, and banking 38(3), 791-819.

Thorsrud, L. A. (2013). Global and regional business cycles. Shocks and propagations. Working Papers 0012, Centre for Applied Macro- and Petroleum economics (CAMP), BI Norwegian Business School.

Woodford, M. (2003). Optimal interest-rate smoothing. The Review of Economic Studies $70(4), 861-886$.

Woodford, M. (2005). Central bank communication and policy effectiveness. NBER Working Paper Series, 11898. 


\section{Appendices}

\section{Appendix A Data}

Table 5. Data descriptions, sources, and transformations. All variables are collected on a monthly frequency, and we only use non-adjusted variables (e.g., not subject to seasonal adjustments). The transformation codes are as follows: 0 - the variable is kept in levels, 2 - the variable is in first differences, 9 - the variable is in year-on-year growth rates.

\begin{tabular}{|c|c|c|c|c|}
\hline Mnemonic & Country & Name/Type & Source & Transformation \\
\hline AU_CCI & Australia & ANZ-ROY MORGAN Consumer confidence rating & Datastream & 0 \\
\hline AU_ICI & Australia & NAB BUSINESS SURVEY: Business confidence & Datastream & 0 \\
\hline AU_IP & Australia & Industrial production (\% YOY) & Datastream & 0 \\
\hline AU_MM & Australia & Interest rates: Money market rate & Datastream & 2 \\
\hline AU_SP & Australia & 10-year bond yield \& 3-month bank bill & Datastream & 0 \\
\hline AU_ST & Australia & Standard and Poors (S\&P)/ASX & Datastream & 9 \\
\hline EU_CCI & Europe & Consumer confidence indicator (EA17) & Datastream & 0 \\
\hline EU_CPI & Europe & HICP - All items (EA19) & Datastream & 9 \\
\hline EU_ICI & Europe & Industrial confidence indicator (EA17) & Datastream & 0 \\
\hline EU_IP & Europe & Industrial production - construction (\%YOY) & Datastream & 0 \\
\hline EU_MM & Europe & Interest rates: Money market rate & Datastream & 2 \\
\hline EU_ST & Europe & Euro Stoxx 50 & Datastream & 9 \\
\hline NO_CPI & Norway & CPI- All items & Datastream & 9 \\
\hline NO_EU_EXC & Norway & EU/NOK exchange rate & Datastream & 9 \\
\hline NO_IP & Norway & Industrial production (\%YOY) & Datastream & 0 \\
\hline NO_MM & Norway & Norwegian interbank offer rate, 3-months & Datastream & 2 \\
\hline NO_SP & Norway & 10-year government bond \& 3-month Treasury Bill & Datastream & 0 \\
\hline NO_ST & Norway & Oslo Stock Exchange Benchmark Index & Datastream & 9 \\
\hline NO_TW_EXC & Norway & Trade weighted exchange rate Index & Datastream & 9 \\
\hline NO_US_EXC & Norway & USD/NOK exchange rate & Datastream & 9 \\
\hline NZ_AU_EXC & New Zealand & $\mathrm{AD} / \mathrm{NZD}$ exchange rate & Datastream & 9 \\
\hline NZ_CCI & New Zealand & Consumer confidence indicator & Datastream & 0 \\
\hline NZ_CPI & New Zealand & CPI - Food & Datastream & 9 \\
\hline NZ_ICI & New Zealand & NBNZ BUSINESS SURVEY: Business confidence & Datastream & 0 \\
\hline NZ_MM & New Zealand & Interest rates: Money market rate & Datastream & 2 \\
\hline NZ_SP & New Zealand & 10-year \& 3-month bank bill & Datastream & 0 \\
\hline NZ_ST & New Zealand & All Share Price Index & Datastream & 9 \\
\hline NZ_TW_EXC & New Zealand & Trade weighted exchange rate index & Datastream & 9 \\
\hline NZ_US_EXC & New Zealand & USD/NZD exchange rate & Datastream & 9 \\
\hline OIL & & Crude Oil Brent Spot Price & Datastream & 9 \\
\hline SW_CCI & Sweden & Consumer confidence indicator & Datastream & 0 \\
\hline SW_CPI & Sweden & CPI - All items & Datastream & 9 \\
\hline SW_EU_EXC & Sweden & EU/SEK exchange rate & Datastream & 9 \\
\hline SW_ICI & Sweden & Industrial confidence indicator & Datastream & 0 \\
\hline SW_IP & Sweden & Industrial production (\%YOY) & Datastream & 0 \\
\hline SW_MM & Sweden & Interest rates: Money market rate & Datastream & 2 \\
\hline SW_SP & Sweden & 10-year government bond \& 3-month Treasury Bill & Datastream & 0 \\
\hline SW_ST & Sweden & Stockholm Stock Exchange Affarsvarlden Index & Datastream & 9 \\
\hline SW_TW_EXC & Sweden & Trade weighted exchange rate Index & Datastream & 9 \\
\hline SW_US_EXC & Sweden & USD/SEK exchange rate & Datastream & 9 \\
\hline US_CCI & USA & University of Michigan Consumer Expectation Index & Datastream & 0 \\
\hline US_CPI & USA & CPI - All items & Datastream & 9 \\
\hline US_FED & USA & U.S. National Activity Index & Datastream & 0 \\
\hline US_IP & USA & Industrial production (\%YOY) & Datastream & 0 \\
\hline US_MM & USA & Interest rates: Money market rate & Datastream & 2 \\
\hline US_SP & USA & 10-year treasury \& FED Funds rate & Datastream & 0 \\
\hline US_ST & USA & S\&P 500 composite & Datastream & 9 \\
\hline VOL & & VSTOXX Volatility index & Datastream & 0 \\
\hline
\end{tabular}


Table 6. Publication dates for interest rate forecasts. Each date refers to the publication dates for the four monetary policy reports collected each year with published forecasts. The interest rate projections published by the RBNZ, NB and SR are the 90-bank bill rate, the key policy rate (foliorenten), and the repo rate, respectively.

\begin{tabular}{|c|c|c|c|c|c|c|c|}
\hline Year & RBNZ & NB & $\mathrm{SR}$ & Year & RBNZ & NB & SR \\
\hline $1999 / 1$ & 17/03/1999 & & & $2008 / 1$ & $06 / 03 / 2008$ & $13 / 03 / 2008$ & $23 / 04 / 2008$ \\
\hline $1999 / 2$ & $19 / 05 / 1999$ & & & $2008 / 2$ & $05 / 06 / 2008$ & $25 / 06 / 2008$ & $03 / 07 / 2008$ \\
\hline $1999 / 3$ & $18 / 08 / 1999$ & & & $2008 / 3$ & $11 / 09 / 2008$ & $29 / 10 / 2008$ & $23 / 10 / 2008$ \\
\hline $1999 / 4$ & $17 / 11 / 1999$ & & & $2008 / 4$ & $04 / 12 / 2008$ & $17 / 12 / 2008$ & $04 / 12 / 2008$ \\
\hline $2000 / 1$ & $15 / 03 / 2000$ & & & $2009 / 1$ & $12 / 03 / 2009$ & $25 / 03 / 2009$ & $21 / 04 / 2009$ \\
\hline $2000 / 2$ & $17 / 05 / 2000$ & & & $2009 / 2$ & $11 / 06 / 2009$ & $17 / 06 / 2009$ & $02 / 07 / 2009$ \\
\hline $2000 / 3$ & $16 / 08 / 2000$ & & & $2009 / 3$ & $10 / 09 / 2009$ & $28 / 10 / 2009$ & $22 / 10 / 2009$ \\
\hline $2000 / 4$ & $06 / 12 / 2000$ & & & $2009 / 4$ & $10 / 12 / 2009$ & na & $16 / 12 / 2009$ \\
\hline $2001 / 1$ & $14 / 03 / 2001$ & & & $2010 / 1$ & $11 / 03 / 2010$ & $24 / 03 / 2010$ & $20 / 04 / 2010$ \\
\hline $2001 / 2$ & $16 / 05 / 2001$ & & & $2010 / 2$ & $10 / 06 / 2010$ & $23 / 06 / 2010$ & $01 / 07 / 2010$ \\
\hline $2001 / 3$ & $15 / 08 / 2001$ & & & $2010 / 3$ & $16 / 09 / 2010$ & $27 / 10 / 2010$ & $26 / 10 / 2010$ \\
\hline $2001 / 4$ & $14 / 11 / 2001$ & & & $2010 / 4$ & $09 / 12 / 2010$ & na & $14 / 12 / 2010$ \\
\hline $2002 / 1$ & $20 / 03 / 2002$ & & & $2011 / 1$ & $10 / 03 / 2011$ & $16 / 03 / 2011$ & $20 / 04 / 2011$ \\
\hline $2002 / 2$ & $15 / 05 / 2002$ & & & $2011 / 2$ & 09/06/2011 & $22 / 06 / 2011$ & $05 / 07 / 2011$ \\
\hline $2002 / 3$ & $14 / 08 / 2002$ & & & $2011 / 3$ & $15 / 09 / 2011$ & $19 / 10 / 2011$ & $27 / 10 / 2011$ \\
\hline $2002 / 4$ & $20 / 11 / 2002$ & & & $2011 / 4$ & $08 / 12 / 2011$ & na & $20 / 12 / 2011$ \\
\hline $2003 / 1$ & $06 / 03 / 2003$ & & & $2012 / 1$ & $08 / 03 / 2012$ & $14 / 03 / 2012$ & $18 / 04 / 2012$ \\
\hline $2003 / 2$ & $05 / 06 / 2003$ & & & $2012 / 2$ & $14 / 06 / 2012$ & $20 / 06 / 2012$ & $04 / 07 / 2012$ \\
\hline $2003 / 3$ & $04 / 09 / 2003$ & & & $2012 / 3$ & $13 / 09 / 2012$ & $31 / 10 / 2012$ & $25 / 10 / 2012$ \\
\hline $2003 / 4$ & $04 / 12 / 2003$ & & & $2012 / 4$ & $06 / 12 / 2012$ & na & $18 / 12 / 2012$ \\
\hline $2004 / 1$ & $11 / 03 / 2004$ & & & $2013 / 1$ & $13 / 03 / 2013$ & $14 / 03 / 2013$ & $17 / 04 / 2013$ \\
\hline $2004 / 2$ & $10 / 06 / 2004$ & & & $2013 / 2$ & $12 / 06 / 2013$ & $20 / 06 / 2013$ & $03 / 07 / 2013$ \\
\hline $2004 / 3$ & $09 / 09 / 2004$ & & & $2013 / 3$ & $11 / 08 / 2013$ & $19 / 09 / 2013$ & $24 / 10 / 2013$ \\
\hline $2004 / 4$ & $09 / 12 / 2004$ & & & $2013 / 4$ & $11 / 12 / 2013$ & $05 / 12 / 2013$ & $17 / 12 / 2013$ \\
\hline $2005 / 1$ & $10 / 03 / 2005$ & & & $2014 / 1$ & $12 / 03 / 2014$ & $27 / 03 / 2014$ & $09 / 04 / 2014$ \\
\hline $2005 / 2$ & $09 / 06 / 2005$ & & & $2014 / 2$ & $11 / 05 / 2014$ & $19 / 06 / 2014$ & $03 / 07 / 2014$ \\
\hline $2005 / 3$ & $15 / 09 / 2005$ & $02 / 11 / 2005$ & & $2014 / 3$ & $10 / 09 / 2014$ & $18 / 09 / 2014$ & $28 / 10 / 2014$ \\
\hline $2005 / 4$ & $08 / 12 / 2005$ & na & & $2014 / 4$ & $10 / 12 / 2014$ & $11 / 12 / 2014$ & $16 / 12 / 2014$ \\
\hline $2006 / 1$ & $09 / 03 / 2006$ & $16 / 03 / 2006$ & & $2015 / 1$ & $11 / 03 / 2015$ & $19 / 03 / 2015$ & $29 / 04 / 2015$ \\
\hline $2006 / 2$ & $08 / 06 / 2006$ & $29 / 06 / 2006$ & & $2015 / 2$ & $11 / 06 / 2015$ & $18 / 06 / 2015$ & $02 / 07 / 2015$ \\
\hline $2006 / 3$ & $14 / 09 / 2006$ & $01 / 11 / 2006$ & & $2015 / 3$ & $10 / 09 / 2015$ & $24 / 09 / 2015$ & $28 / 10 / 2015$ \\
\hline $2006 / 4$ & $07 / 12 / 2006$ & na & & $2015 / 4$ & $10 / 12 / 2015$ & $17 / 12 / 2015$ & $15 / 12 / 2015$ \\
\hline $2007 / 1$ & $08 / 03 / 2007$ & $15 / 03 / 2007$ & $15 / 02 / 2007$ & & & & \\
\hline $2007 / 2$ & $07 / 06 / 2007$ & $27 / 06 / 2007$ & $20 / 06 / 2007$ & & & & \\
\hline $2007 / 3$ & $13 / 09 / 2007$ & $31 / 10 / 2007$ & $30 / 10 / 2007$ & & & & \\
\hline $2007 / 4$ & $06 / 12 / 2007$ & na & $19 / 12 / 2007$ & & & & \\
\hline
\end{tabular}




\section{A.1 Interest rate data and details on construction}

Important to our set up is the construction of a real-time data-set of interest rate projections from the published monetary policy reports issued by the central banks. From this, we construct and store separately the one-step ahead, the two-steps ahead, the three-steps ahead and the four steps-ahead real-time forecasts for the interest rates. ${ }^{19} \mathrm{~A}$ forecast revision will then be the difference between a forecast made in one quarter, and the counterpart (updated) forecast made in the following quarter.

Starting with New Zealand, since 1997, RBNZ has published regular quarterly projections in its Monetary Policy Statement, typically late in each quarter; March, June, September and December. We choose to start the analysis in March 1999, which is the date the RBNZ adopted the Official Cash Rate (OCR).

In Norway, NB started to publish interest rate projections in the monetary policy reports in 2005. Up until 2012, the forecasts were published three times a year; March, June and October. ${ }^{20}$ Since 2012, the forecast are published four times a year; March, June, September and December. Hence, since 2012, the timing of the published forecasts is consistent with those of the RBNZ. The period prior to 2012, however, is slightly more complicated, since there is only one report published in the fall (October). To deal with this, we construct from the October report two forecast series; a series of forecasts for Q4 and onwards as if it was constructed in Q3 (originally the nowcast for Q4, the 1-steps ahead forecast for Q1, the 2-steps ahead forecast for Q2 etc.) and a series of forecasts for Q1 and onwards as if it was constructed in Q4 (originally the 1-steps ahead forecast for Q1, the 2-steps ahead forecast for Q2 and the 3-steps ahead forecast for Q3 etc.). This gives NB both an advantage and a disadvantage. It has a one month information advantage relative to the other central banks since the 1-step ahead forecast for Q4 is actually a nowcast published one month into Q4 (October). On the other hand, regarding the forecast for Q1 (and onwards), NB has a two-month information disadvantage, in that the forecast is released in October rather than in December as for the other countries.

In Sweden SR started publishing its interest rate path for the policy rate in February 2007. The forecasts are published in the Monetary Policy Report and the Monetary Policy Update which, except for the first year, are published six times a years (February, April, June/July, September, October and December). However, to be consistent with

${ }^{19}$ Note that the forecast horizons in each report are not fixed, varying from one-step (i.e., one quarter) ahead, normally ending up to 8- or 12-steps ahead.

${ }^{20}$ The exception was in 2008, when Norges Bank published an updated forecast in December due to the financial crisis. 
the other two countries; we use the interest rate paths published in April, June/July, October and December (report number $1^{*}, 2,3$, and $3^{*}$ respectively). For the first year, the publication months are February, June, October and December. That means that for some of the reports, SR has up to one additional month of available data relative to NB and RBNZ, giving SR an advantage in the exercise. However, from Table 6 we see that many of the reports are published early in the months, giving SR in practice only a few days advantage.

\section{A.2 VAR data}

When estimating the VAR in Section 4 of the main paper, we include the output gap, inflation, the real exchange rate, stock prices, and the change in the interest rate. The output gap is computed using real GDP and the Hodrick Prescott (HP) filter with a smoothing parameter of 40000. The results reported are robust to using a smoothing parameter of 1600, or a linear deterministic trend. For New Zealand and Norway, the inflation measures include all items and are transformed to year-on-year growth. In Sweden the CPI index is significantly affected by institutional arrangements in the housing market. For this reason we use the GDP deflator for this country, but the same transformation as for the other countries. Asset prices reflect the main stock exchange indexes in each country, and are measured as year-on-year returns. Both output, prices and asset prices are collected from the national statistics offices for the various countries. The real exchange rates are collected from the Bank for International Settlements (BIS), and we use the rates from the narrow basket composition. The various interest rate measures are discussed in Section 4.2, and collected from the three different central banks, respectively. 


\section{Appendix B Additional results}

Table 7. Forecast errors and factor predictability. Panel A reports the results when only variables significant at the $10 \%$ level are used to construct the respective factors. Panel B reports the results when the factors used are made orthogonal to each other. Standard errors are reported in parentheses. *, **, and ${ }^{* * *}$, indicate that coefficients are statistically significant at the $10 \%, 5 \%$, and $1 \%$ level, respectively. Test statistics are computed using a residual bootstrap.

\begin{tabular}{|c|c|c|c|c|c|c|}
\hline & \multicolumn{2}{|c|}{ New Zealand } & \multicolumn{2}{|c|}{ Norway } & \multicolumn{2}{|c|}{ Sweden } \\
\hline & $r_{12, t+1}$ & $r_{34, t+1}$ & $r_{12, t+1}$ & $r_{34, t+1}$ & $r_{12, t+1}$ & $r_{34, t+1}$ \\
\hline \multicolumn{7}{|c|}{ Panel A: $10 \%$ significant level } \\
\hline$\gamma_{0}$ & $\begin{array}{c}0.66^{* * *} \\
(0.12)\end{array}$ & $\begin{array}{c}1.02^{* * * *} \\
(0.07)\end{array}$ & $\begin{array}{l}0.32^{*} \\
(0.16)\end{array}$ & $\begin{array}{c}0.62^{* * *} \\
(0.12)\end{array}$ & $\begin{array}{c}0.54^{* * *} \\
(0.16)\end{array}$ & $\begin{array}{c}0.88^{* * *} \\
(0.10)\end{array}$ \\
\hline$\beta^{I}$ & $\begin{array}{c}0.27^{* * *} \\
(0.06)\end{array}$ & $\begin{array}{c}-0.50^{* * *} \\
(0.13)\end{array}$ & $\begin{array}{c}0.29 * * \\
(0.10)\end{array}$ & $\begin{array}{c}0.16 \\
(0.24)\end{array}$ & $\begin{array}{c}0.14 \\
(0.10)\end{array}$ & $\begin{array}{c}0.60^{* *} \\
(0.27)\end{array}$ \\
\hline$\beta^{D}$ & $\begin{array}{c}0.13 \\
(0.08)\end{array}$ & $\begin{array}{c}0.01 \\
(0.11)\end{array}$ & $\begin{array}{l}-0.09 \\
(0.10)\end{array}$ & $\begin{array}{c}0.29 \\
(0.25)\end{array}$ & $\begin{array}{c}0.08 \\
(0.11)\end{array}$ & $\begin{array}{l}-0.16 \\
(0.26)\end{array}$ \\
\hline$R_{a d j}^{2}$ & 0.56 & 0.77 & 0.48 & 0.57 & 0.50 & 0.73 \\
\hline $\mathrm{N}$ & 65 & 63 & 33 & 31 & 33 & 31 \\
\hline \multicolumn{7}{|c|}{ Panel B: $10 \%$ significant level and orthogonal factors } \\
\hline$\gamma_{0}$ & $\begin{array}{c}0.66^{* * *} \\
(0.12)\end{array}$ & $\begin{array}{c}1.02^{* * *} \\
(0.07)\end{array}$ & $\begin{array}{c}0.32^{* *} \\
(0.16)\end{array}$ & $\begin{array}{c}0.62^{* * *} \\
(0.12)\end{array}$ & $\begin{array}{c}0.54^{* * *} \\
(0.16)\end{array}$ & $\begin{array}{c}0.88^{* * *} \\
(0.10)\end{array}$ \\
\hline$\beta^{I}$ & $\begin{array}{c}0.24^{* * *} \\
(0.07)\end{array}$ & $\begin{array}{c}-0.49^{* * *} \\
(0.10)\end{array}$ & $\begin{array}{c}0.21^{* * *} \\
(0.05)\end{array}$ & $\begin{array}{c}0.41^{* * *} \\
(0.12)\end{array}$ & $\begin{array}{c}0.20^{* * *} \\
(0.06)\end{array}$ & $\begin{array}{c}0.45^{* * *} \\
(0.10)\end{array}$ \\
\hline$\beta^{D}$ & $\begin{array}{c}0.13 \\
(0.08)\end{array}$ & $\begin{array}{c}0.01 \\
(0.11)\end{array}$ & $\begin{array}{l}-0.09 \\
(0.10)\end{array}$ & $\begin{array}{c}0.29 \\
(0.25)\end{array}$ & $\begin{array}{c}0.08 \\
(0.11)\end{array}$ & $\begin{array}{l}-0.16 \\
(0.26)\end{array}$ \\
\hline$R_{a d j}^{2}$ & 0.56 & 0.77 & 0.48 & 0.57 & 0.50 & 0.73 \\
\hline $\mathrm{N}$ & 65 & 63 & 33 & 31 & 33 & 31 \\
\hline
\end{tabular}


Table 8. Inflation, forecast revisions and factor predictability. Panel A reports the results when all foreign and domestic variables are used when constructing one international and one domestic factor. Panel B reports the results when only variables significant at the $10 \%$ level are used to construct the respective factors (missing values indicate that factors could not be constructed under this assumption). In both instances, the factors are made orthogonal to each other. Standard errors are reported in parentheses. * ${ }^{* *}$, and $* * *$, indicate that coefficients are statistically significant at the $10 \%, 5 \%, 1 \%$ level, respectively. Test statistics are computed using a residual bootstrap.

\begin{tabular}{|c|c|c|c|c|c|c|}
\hline & \multicolumn{2}{|c|}{ New Zealand } & \multicolumn{2}{|c|}{ Norway } & \multicolumn{2}{|c|}{ Sweden } \\
\hline & $r_{12, t+1}$ & $r_{34, t+1}$ & $r_{12, t+1}$ & $r_{34, t+1}$ & $r_{12, t+1}$ & $r_{34, t+1}$ \\
\hline \multicolumn{7}{|c|}{ Panel A: All variables and orthogonal factors } \\
\hline$\gamma_{0}$ & $\begin{array}{c}0.02 \\
(0.13)\end{array}$ & $\begin{array}{c}0.64^{* * *} \\
(0.11)\end{array}$ & $\begin{array}{l}-0.29 \\
(0.19)\end{array}$ & $\begin{array}{l}-0.27 \\
(0.19)\end{array}$ & $\begin{array}{c}0.01 \\
(0.24)\end{array}$ & $\begin{array}{l}-0.08 \\
(0.20)\end{array}$ \\
\hline$\beta^{I}$ & $\begin{array}{c}0.04 \\
(0.07)\end{array}$ & $\begin{array}{c}-0.16 \\
(0.09)\end{array}$ & $\begin{array}{c}0.09 \\
(0.10)\end{array}$ & $\begin{array}{c}0.23^{* *} \\
(0.10)\end{array}$ & $\begin{array}{c}0.17 \\
(0.11)\end{array}$ & $\begin{array}{c}0.16 \\
(0.13)\end{array}$ \\
\hline$\beta^{D}$ & $\begin{array}{c}0.01 \\
(0.09)\end{array}$ & $\begin{array}{c}0.15 \\
(0.13)\end{array}$ & $\begin{array}{l}-0.02 \\
(0.13)\end{array}$ & $\begin{array}{l}-0.12 \\
(0.12)\end{array}$ & $\begin{array}{l}-0.20 \\
(0.17)\end{array}$ & $\begin{array}{l}-0.27 \\
(0.22)\end{array}$ \\
\hline$R_{a d j}^{2}$ & -0.04 & 0.40 & -0.01 & 0.11 & 0.08 & 0.00 \\
\hline $\mathrm{N}$ & 65 & 63 & 31 & 29 & 30 & 27 \\
\hline \multicolumn{7}{|c|}{ Panel B: 10\% significant level and orthogonal factors } \\
\hline$\gamma_{0}$ & & $\begin{array}{c}0.60^{* * *} \\
(0.10)\end{array}$ & & $\begin{array}{l}-0.28 \\
(0.17)\end{array}$ & & $\begin{array}{l}-0.12 \\
(0.16)\end{array}$ \\
\hline$\beta^{I}$ & & $\begin{array}{c}0.27^{* * *} \\
(0.09)\end{array}$ & & $\begin{array}{c}0.30^{* * *} \\
(0.09)\end{array}$ & & $\begin{array}{c}0.38^{* * *} \\
(0.10)\end{array}$ \\
\hline$\beta^{D}$ & & $\begin{array}{c}-0.21^{*} \\
(0.10)\end{array}$ & & $\begin{array}{l}-0.16 \\
(0.12)\end{array}$ & & $\begin{array}{c}-0.26^{* *} \\
(0.11)\end{array}$ \\
\hline$R_{a d j}^{2}$ & & 0.48 & & 0.29 & & 0.38 \\
\hline $\mathrm{N}$ & & 63 & & 29 & & 27 \\
\hline
\end{tabular}


Table 9. Output/output gap, forecast revisions and factor predictability. See Table 8 for further explanations.

\begin{tabular}{|c|c|c|c|c|c|c|}
\hline & \multicolumn{2}{|c|}{ New Zealand } & \multicolumn{2}{|c|}{ Norway } & \multicolumn{2}{|c|}{ Sweden } \\
\hline & $r_{12, t+1}$ & $r_{34, t+1}$ & $r_{12, t+1}$ & $r_{34, t+1}$ & $r_{12, t+1}$ & $r_{34, t+1}$ \\
\hline \multicolumn{7}{|c|}{ Panel A: All variables and orthogonal factors } \\
\hline$\gamma_{0}$ & $\begin{array}{l}-0.02 \\
(0.16)\end{array}$ & $\begin{array}{l}-0.20 \\
(0.15)\end{array}$ & $\begin{array}{l}-0.11 \\
(0.17)\end{array}$ & $\begin{array}{c}0.12 \\
(0.22)\end{array}$ & $\begin{array}{c}-0.17 \\
(0.19)\end{array}$ & $\begin{array}{c}0.19 \\
(0.21)\end{array}$ \\
\hline$\beta^{I}$ & $\begin{array}{l}-0.15 \\
(0.09)\end{array}$ & $\begin{array}{c}0.32^{* * *} \\
(0.10)\end{array}$ & $\begin{array}{l}0.09^{*} \\
(0.05)\end{array}$ & $\begin{array}{l}-0.02 \\
(0.10)\end{array}$ & $\begin{array}{c}0.70^{* * *} \\
(0.20)\end{array}$ & $\begin{array}{c}0.05 \\
(0.14)\end{array}$ \\
\hline$\beta^{D}$ & $\begin{array}{l}-0.10 \\
(0.14)\end{array}$ & $\begin{array}{c}0.18 \\
(0.14)\end{array}$ & $\begin{array}{c}0.03 \\
(0.06)\end{array}$ & $\begin{array}{c}0.01 \\
(0.13)\end{array}$ & $\begin{array}{l}-0.40 \\
(0.30)\end{array}$ & $\begin{array}{c}0.18 \\
(0.24)\end{array}$ \\
\hline$R_{a d j}^{2}$ & 0.01 & 0.13 & 0.02 & -0.10 & 0.27 & -0.05 \\
\hline $\mathrm{N}$ & 54 & 52 & 33 & 31 & 32 & 30 \\
\hline \multicolumn{7}{|c|}{ Panel B: 10 significant level and orthogonal factors } \\
\hline$\gamma_{0}$ & & $\begin{array}{c}-0.34^{* * *} \\
(0.14)\end{array}$ & & & $\begin{array}{l}-0.22 \\
(0.18)\end{array}$ & $\begin{array}{l}-0.04 \\
(0.14)\end{array}$ \\
\hline$\beta^{I}$ & & $\begin{array}{c}0.47^{* * *} \\
(0.10)\end{array}$ & & & $\begin{array}{c}0.77^{* * *} \\
(0.18)\end{array}$ & $\begin{array}{c}0.44^{* * *} \\
(0.09)\end{array}$ \\
\hline$\beta^{D}$ & & $\begin{array}{c}0.16 \\
(0.17)\end{array}$ & & & $\begin{array}{l}0.59^{*} \\
(0.30)\end{array}$ & $\begin{array}{c}-0.37 * * * \\
(0.11)\end{array}$ \\
\hline$R_{a d j}^{2}$ & & 0.28 & & & 0.37 & 0.52 \\
\hline $\mathrm{N}$ & & 52 & & & 32 & 30 \\
\hline
\end{tabular}

Table 10. Contemporaneous correlations between the $r_{12, t+1}$ forecast revisions and various interest rate measures. $*{ }^{* *}$, and ${ }^{* * *}$, indicate that coefficients are statistically significant at the $10 \%, 5 \%, 1 \%$ level, respectively. The last row in the table reports the number of observations.

\begin{tabular}{|c|c|c|c|c|c|c|c|c|}
\hline \multicolumn{3}{|c|}{ New Zealand } & \multicolumn{3}{|c|}{ Norway } & \multicolumn{3}{|c|}{ Sweden } \\
\hline 3 month & 1 year & 2 year & 3 month & 3 year & 5 year & 3 month & 2 year & 5 year \\
\hline $0.528^{* * *}$ & $0.437^{* * *}$ & $0.345^{* * *}$ & $0.873^{* * *}$ & $0.628^{* * *}$ & $0.467 * *$ & $0.783^{* * *}$ & $0.560 * * *$ & 0.213 \\
\hline 55 & 55 & 55 & 29 & 29 & 29 & 26 & 26 & 26 \\
\hline
\end{tabular}




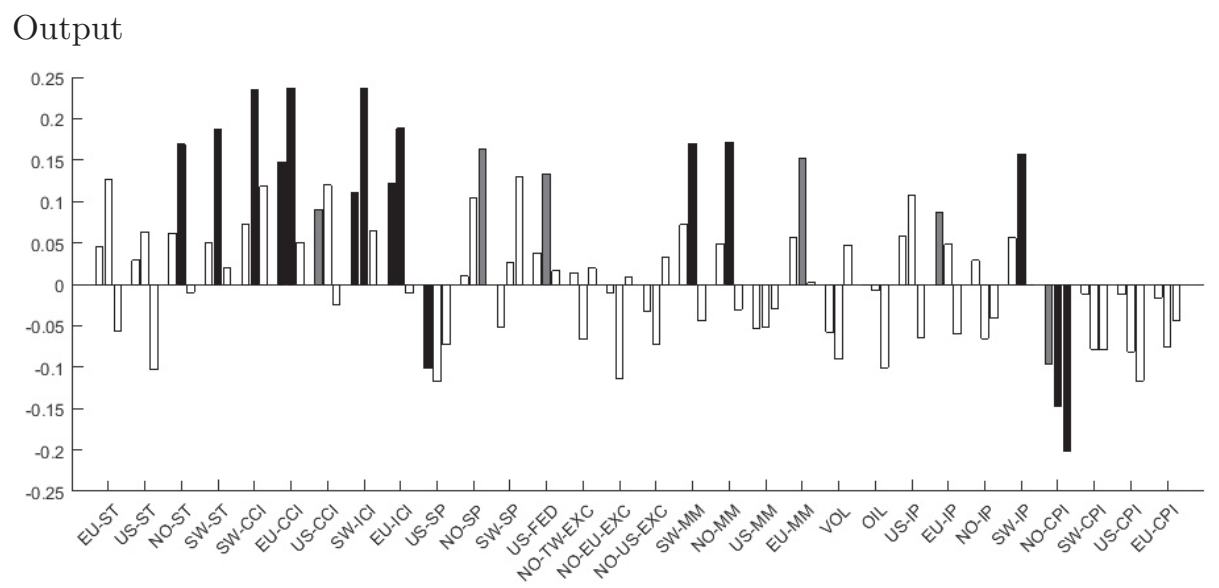

Inflation

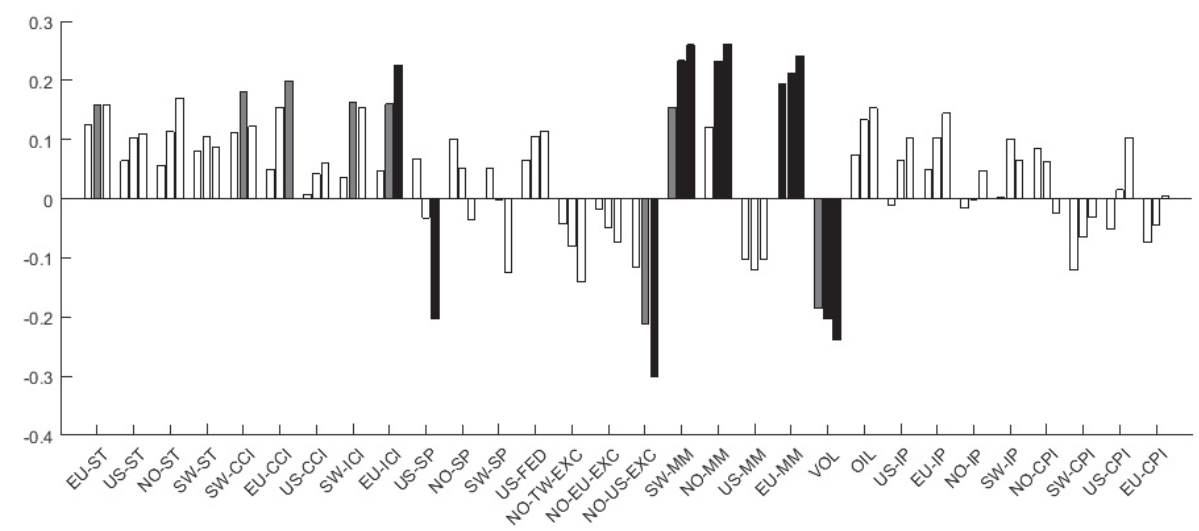

Figure 5. Forecast revisions of inflation and output and ADL regression results in Norway. See Figure 2 for further explanations. 


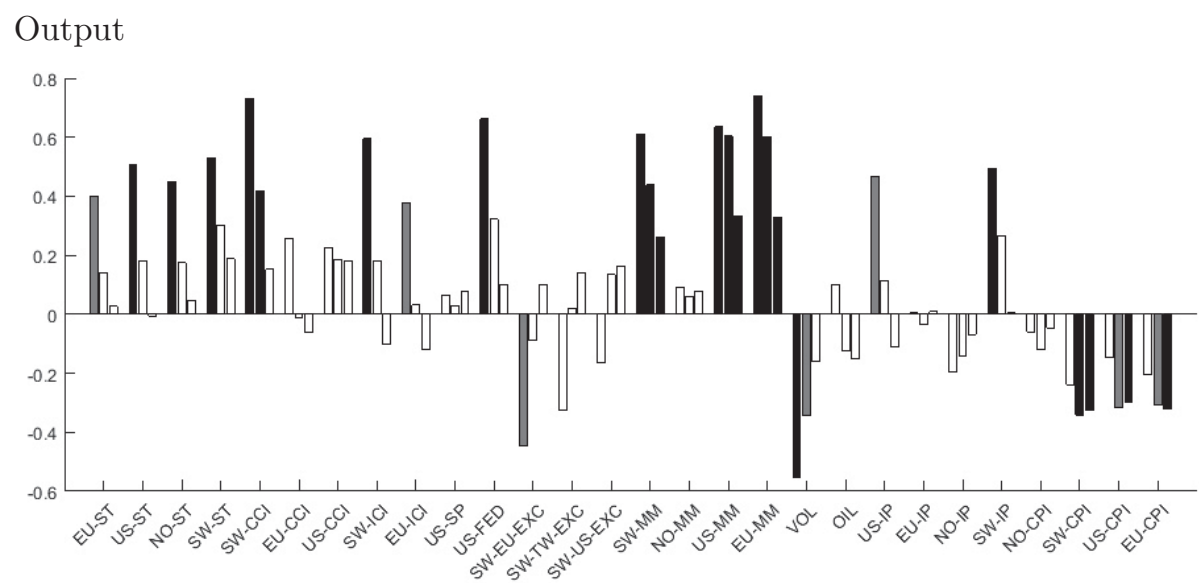

Inflation

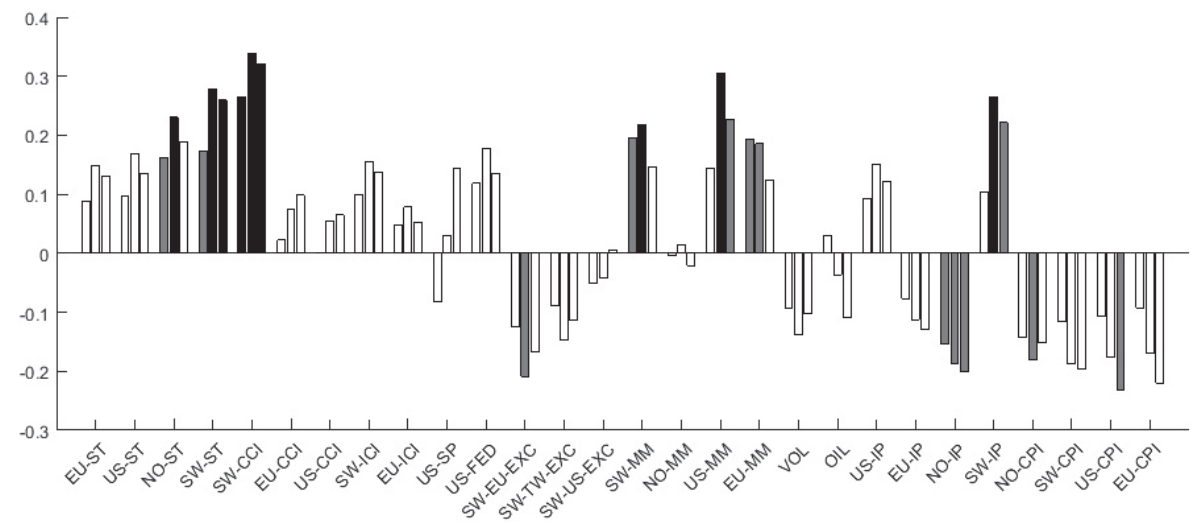

Figure 6. Forecast revisions of inflation and output and ADL regression results in Sweden. See Figure 2 for further explanations. 


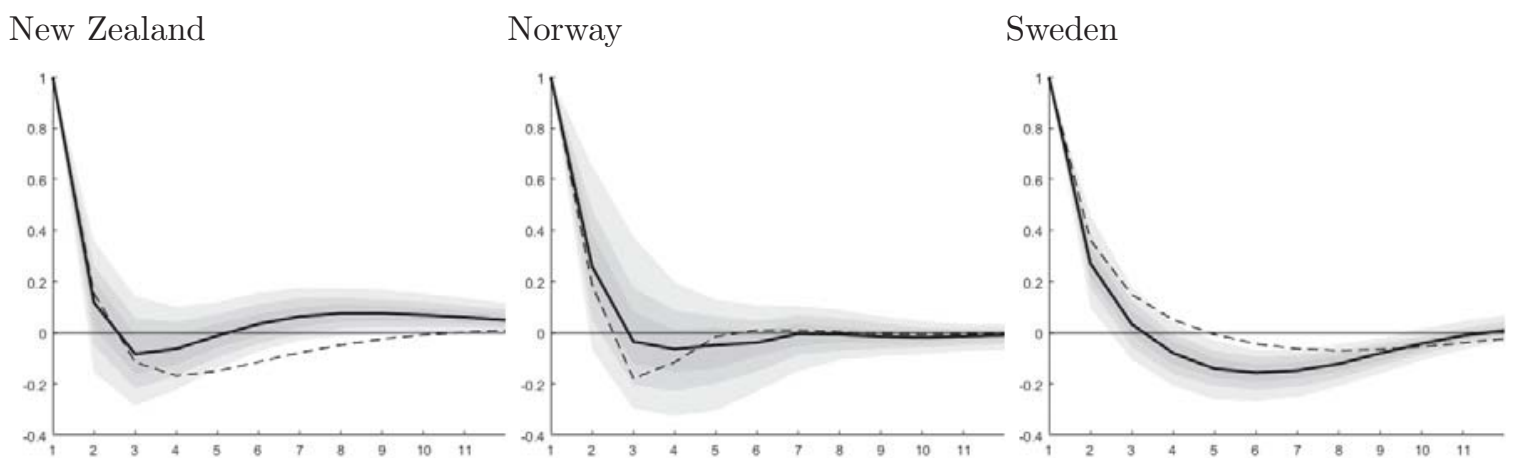

Figure 7. Impulse responses of the interest rate following a monetary policy shock. See Figure 4 for further explanations.

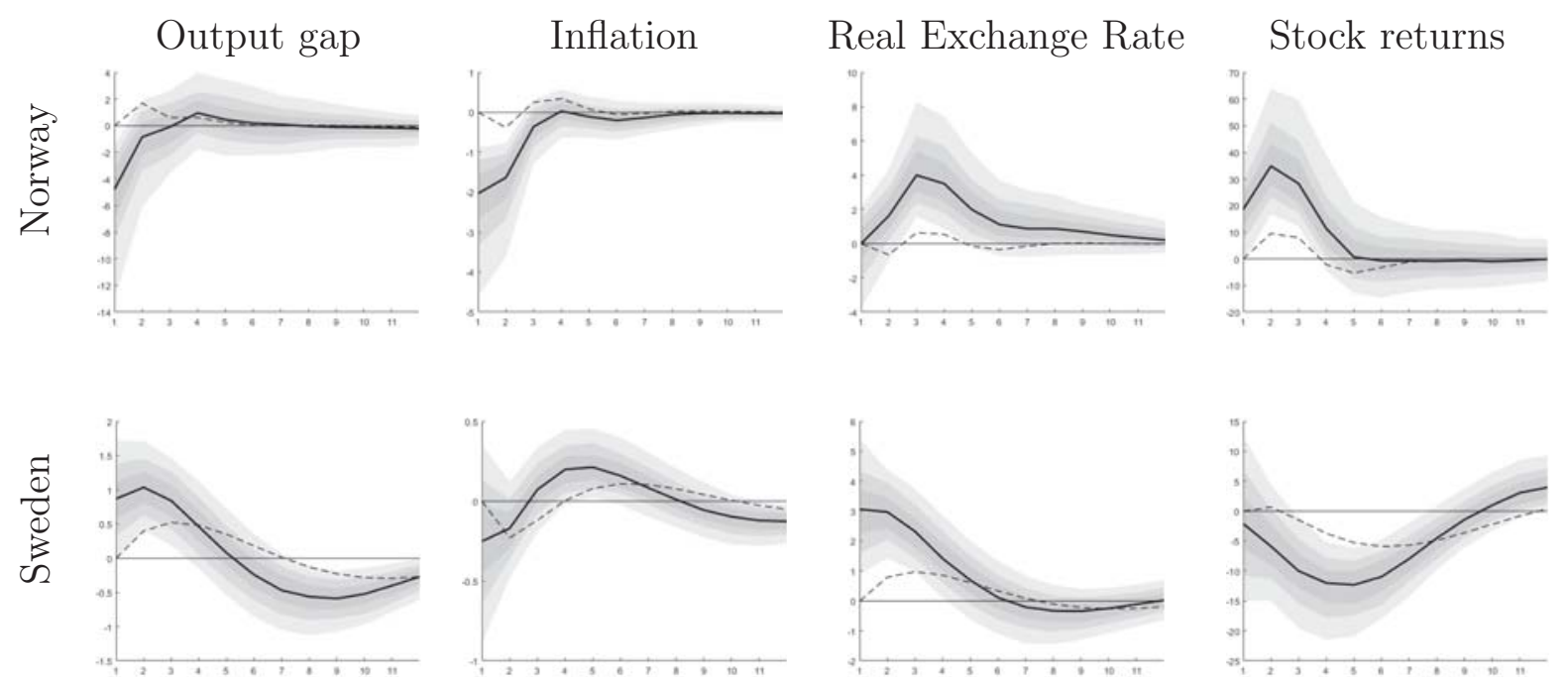

Figure 8. Norway and Sweden: Impulse responses to a monetary policy shock. See Figure 4 for further explanations. 


\section{B.1 VAR robustness}

When constructing the instruments used in Section 4.2 of the main paper, we used the predictable part of the forecast error at the two-step ahead horizon. In principle, we could also have used the longer horizon forecast errors when constructing the instruments. However, we refrained from doing so for two reasons. First, the sample with forecast errors available becomes shorter as the horizon increases, and we loose additional observations when constructing these alternative instruments. As the samples used to construct the instruments are already rather short, see Table 4, we wanted to avoid shrinking it further. Second, choosing longer horizons makes it more likely that the influence of the predominantly international indicators/factors used to predict the forecast errors, has made its way into the economy through other channels than as monetary policy errors. In turn, this might make it more difficult to separately identify a monetary policy shock effect.

Still, as a robustness check to the choice made in Section 4.2, we redid the experiment for New Zealand, for which we have the longest sample. In this robustness exercise we use the same interest rate measure as the one preferred in Table 4, but now also consider instruments constructed based on forecast errors made up to four-steps ahead. As before, two instruments are considered, either one based on a single indicator, or one based on the factor estimates. Figure 9 reports the results for these alternative experiments. As can be seen, for all combinations of instruments and horizons, the output gap falls on impact, and there is no price or exchange rate puzzle. However, in line with our concern described above, there is a tendency towards a faster recovery in output when the predicted values of the longer horizon forecast errors are used as instruments. Likewise, stock returns only respond negatively when the shortest horizon instrument is used.

As a final robustness experiment, we also used an alternative VAR for New Zealand, including a foreign business cycle indicator in the model instead of stock prices. Stock prices are excluded to avoid over-parameterizing the VAR, while the foreign indicator used is the $A U C C I$, i.e., the Australian consumer confidence indicator. The motivation for this experiment stems from the concern that the responses obtained in the benchmark case might be due to omitted variable biases. In particular, it might be the case that by not including a foreign variable directly in the VAR, the IV identified monetary policy shock is actually not a shock, but a misspecification of the model such that systematic foreign influences are not taken into account. However, as shown in Figure 10, our results seem relatively robust with regard to this concern. 


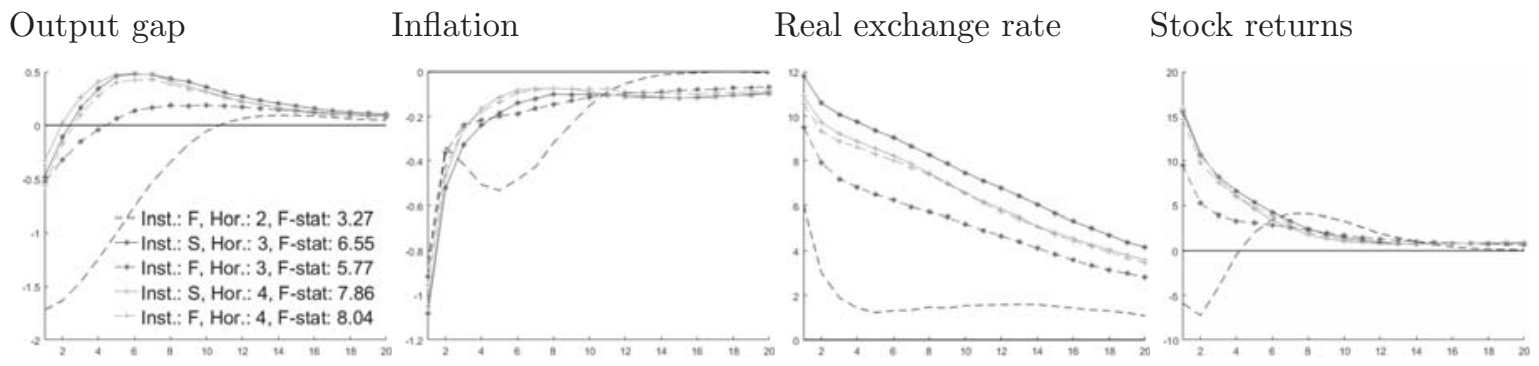

Figure 9. Median impulse responses to a monetary policy shock in New Zealand using alternative instruments and horizons. Inst. refers to the instrument used: single indicator $(\mathrm{S})$, or factors $(\mathrm{F})$. Hor. refers to the forecast error horizon used: two- to four-step ahead.

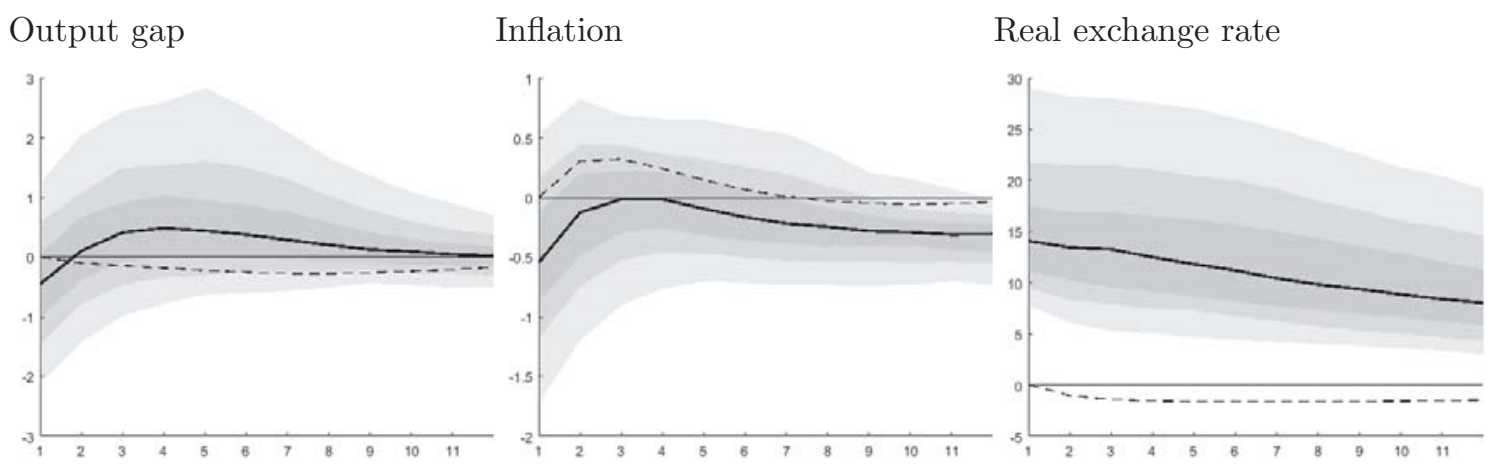

Figure 10. Impulse responses to a monetary policy shock in New Zealand using an alternative VAR with foreign variable instead of stock prices. See Figure 4 for further explanations. 